\title{
Current status of boron neutron capture therapy of high grade gliomas and recurrent head and neck cancer
}

Rolf F Barth ${ }^{1 *}$, M Graca H Vicente ${ }^{2}$, Otto K Harling ${ }^{3}$, W S Kiger III ${ }^{4}$, Kent J Riley ${ }^{5}$, Peter J Binns ${ }^{6}$, Franz M Wagner ${ }^{7}$, Minoru Suzuki ${ }^{8}$, Teruhito Aihara ${ }^{9}$, Itsuro Kato ${ }^{10}$ and Shinji Kawabata ${ }^{11}$

\begin{abstract}
Boron neutron capture therapy (BNCT) is a biochemically targeted radiotherapy based on the nuclear capture and fission reactions that occur when non-radioactive boron-10, which is a constituent of natural elemental boron, is irradiated with low energy thermal neutrons to yield high linear energy transfer alpha particles and recoiling lithium-7 nuclei. Clinical interest in BNCT has focused primarily on the treatment of high grade gliomas, recurrent cancers of the head and neck region and either primary or metastatic melanoma. Neutron sources for BNCT currently have been limited to specially modified nuclear reactors, which are or until the recent Japanese natural disaster, were available in Japan, the United States, Finland and several other European countries, Argentina and Taiwan. Accelerators producing epithermal neutron beams also could be used for BNCT and these are being developed in several countries. It is anticipated that the first Japanese accelerator will be available for therapeutic use in 2013. The major hurdle for the design and synthesis of boron delivery agents has been the requirement for selective tumor targeting to achieve boron concentrations in the range of $20 \mu \mathrm{g} / \mathrm{g}$. This would be sufficient to deliver therapeutic doses of radiation with minimal normal tissue toxicity. Two boron drugs have been used clinically, a dihydroxyboryl derivative of phenylalanine, referred to as boronophenylalanine or "BPA", and sodium borocaptate or "BSH" $\left(\mathrm{Na}_{2} \mathrm{~B}_{12} \mathrm{H}_{11} \mathrm{SH}\right)$. In this report we will provide an overview of other boron delivery agents that currently are under evaluation, neutron sources in use or under development for BNCT, clinical dosimetry, treatment planning, and finally a summary of previous and on-going clinical studies for high grade gliomas and recurrent tumors of the head and neck region. Promising results have been obtained with both groups of patients but these outcomes must be more rigorously evaluated in larger, possibly randomized clinical trials. Finally, we will summarize the critical issues that must be addressed if BNCT is to become a more widely established clinical modality for the treatment of those malignancies for which there currently are no good treatment options.
\end{abstract}

Keywords: Boron neutron capture therapy, Gliomas, Head and neck cancer, Radiation therapy

\section{Introduction}

Boron neutron capture therapy (BNCT) is based on the nuclear capture and fission reactions that occur when boron-10, which is a non-radioactive constituent of natural elemental boron, is irradiated with low energy $(0.025 \mathrm{eV})$ thermal neutrons. This results in the production of high linear energy transfer (LET) alpha

\footnotetext{
* Correspondence: rolf.barth@osumc.edu

'Department of Pathology, The Ohio State University, 165 Hamilton Hall, 1645 Neil Avenue, Columbus, $\mathrm{OH} 43210$, USA

Full list of author information is available at the end of the article
}

particles $\left({ }^{4} \mathrm{He}\right)$ and recoiling lithium-7 $\left({ }^{7} \mathrm{Li}\right)$ nuclei, as shown below.

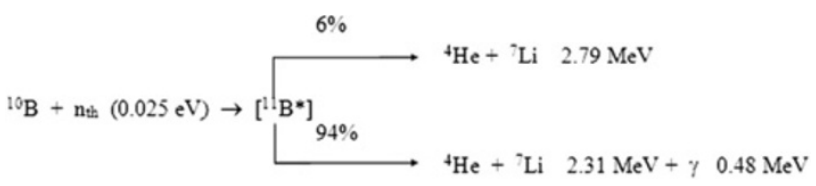

In order to be successful, a sufficient amount of ${ }^{10} \mathrm{~B}$ must be selectively delivered to all tumor cells $(\sim 20 \mu \mathrm{g} / \mathrm{g}$ weight or $\sim 10^{9}$ atoms/cell), and enough thermal neutrons

\section{Biomed Central}

(c) 2012 Barth et al.; licensee BioMed Central Ltd. This is an Open Access article distributed under the terms of the Creative Commons Attribution License (http://creativecommons.org/licenses/by/2.0), which permits unrestricted use, distribution, and reproduction in any medium, provided the original work is properly cited. 
must be absorbed to cause lethal damage from the ${ }^{10} \mathrm{~B}$ $(n, \alpha)^{7} \mathrm{Li}$ capture reaction [1]. The destructive effects of these high energy particles are limited to boron containing cells and since they have very short pathlengths in tissues $(5-9 \mu \mathrm{m})$, in theory BNCT provides a way to selectively destroy malignant cells and spare adjacent normal cells. Clinical interest in BNCT has focused primarily on high grade gliomas [1-3], and more recently on patients with recurrent tumors of the head and neck region [4-7] who have failed conventional therapy. BNCT primarily is a biochemically rather than a physically targeted type of radiation therapy, and, therefore, it should be possible to selectively destroy tumor cells dispersed in normal tissue, providing that sufficient amounts of ${ }^{10} \mathrm{~B}$ and thermal neutrons are delivered to the site of the tumor. In this report, we will provide an update on BNCT, as it relates to the treatment of high grade gliomas and cancers of the head and neck region. We will briefly summarize current developments in the design and synthesis boron delivery agents, neutron sources, clinical dosimetry, treatment planning techniques, and past and ongoing clinical trials in the United States, Japan and Europe and finally, critical issues that must be addressed if BNCT is to be successful. Readers interested in more indepth coverage of these and other topics related to BNCT are referred to the Proceedings of $13^{\text {th }}$ and $14^{\text {th }}$ International Congresses on Neutron Capture Therapy $[8,9]$.

\section{Boron delivery agents}

\section{General requirements}

Research in the area of development of boron-containing delivery agents for BNCT started $\sim 50$ years ago with the investigation of a large number of low molecular weight boron compounds, from which the first generation agents emerged. The most important requirements for a BNCT delivery agent are: 1.) low toxicity and normal tissue uptake, with a tumor:normal tissue and tumor:blood (T:Bl) boron concentration ratios of $\sim 3$; 2.) tumor boron concentration of $\sim 20 \mu \mathrm{g}{ }^{10} \mathrm{~B} / \mathrm{g}$ tumor; 3 .) relatively rapid clearance from blood and normal tissues, and persistence in tumor during neutron irradiations. The only two BNCT delivery agents currently used in clinical trials are sodium mercaptoundecahydro-closo-dodecaborate $\left(\mathrm{Na}_{2} \mathrm{~B}_{12} \mathrm{H}_{11} \mathrm{SH}\right)$, commonly known as sodium borocaptate (BSH), and the boroncontaining amino acid (L)-4-dihydroxy-borylphenylalanine, known as boronophenylalanine or BPA [10]. Neither of these agents adequately fulfills the criteria indicated above, and for this reason third generation agents incorporating one or more polyhedral borane anions or carboranes have been investigated. With the development of new synthetic techniques and increased awareness of the biochemical requirements needed for effective boron containing agents and their modes of delivery, a number of new boron agents have emerged. The major challenge in the development of such agents has been the requirement for selective tumor cell targeting and the delivery of therapeutic boron levels with minimal normal tissue toxicity. The localized and effective destruction of glioblastoma (GBM) cells in the presence of normal brain represents a greater challenge than for malignancies at other anatomic sites. This is due to an additional biological barrier, the blood-brain barrier (BBB), and the highly infiltrative nature of glioma cells and their molecular heterogeneity.

\section{Third generation boron delivery agents}

Recent efforts to improve the selectivity of boron delivery agents has involved incorporating them into tumortargeting molecules, such as peptides, proteins, antibodies, nucleosides, sugars, porphyrins, liposomes and nanoparticles. A compilation of third generation delivery agents of low and high molecular weight is summarized in Table 1 and a recent comprehensive review on this topic [11]. The low molecular weight boron delivery agents include boronated natural amino acids (i.e., BPA derivatives with higher percentage of boron by weight) as well as boronated derivatives of other amino acids, such as aspartic acid, tyrosine, cysteine, methionine and serine [12-14]. Additionally, boron-containing unnatural amino acids also have been investigated because of their higher metabolic stability compared with the natural ones. The boronated derivatives of 1-aminocyclobutane1-carboxylic acid and 1-amino-3-boronocyclopentanecarboxylic acid (designated $\mathrm{ABCPC}$ ) are examples of such compounds [13,14]. Boron-containing linear and cyclic peptides are being investigated because they are usually non-immunogenic, easy to synthesize, and often show low toxicity and high tissue penetrating properties [15]. Of particular interest are peptide ligands for overexpressed receptors on tumor cells, such as the vascular endothelial growth factor receptor (VEGFR), somatostatin receptors and the epidermal growth factor

Table 1 Examples of new low- and high-molecular-weight boron delivery agents currently under evaluation*

\begin{tabular}{|c|c|}
\hline $\begin{array}{l}\text { Boronated unnatural amino } \\
\text { acids [12-14] }\end{array}$ & Carboranyl nucleosides $[16,17]$ \\
\hline $\begin{array}{l}\text { Dodecaborate cluster lipids and } \\
\text { cholesterol derivatives [18] }\end{array}$ & Boronated porphyrins [19-21] \\
\hline $\begin{array}{l}\text { Boron containing immunoliposomes } \\
{[22] \text { and liposomes [23-26] }}\end{array}$ & $\begin{array}{l}\text { Boronated EGF and anti-EGFR } \\
\text { and VEGFR MoAbs [27-33] }\end{array}$ \\
\hline Boronated DNA intercalators [34] & $\begin{array}{l}\text { Boron-containing nanoparticles } \\
{[35,36]}\end{array}$ \\
\hline $\begin{array}{l}\text { Transferrin-polyethylene glycol } \\
\text { (TF-PEG) liposomes }[37,38]\end{array}$ & Carboranyl porphyrazines [39] \\
\hline \multirow{2}{*}{$\begin{array}{l}\text { Dodecahyrdo-closo-dodecaborate } \\
\text { clusters [18] }\end{array}$} & Boronated cyclic peptides [15] \\
\hline & Boron nitride nanotubes [40] \\
\hline
\end{tabular}

* The numbers indicated in brackets are cited in the reference section. 
receptor (EGFR), enzyme substrates and intracellular delivery sequences.

Boron-containing purines, pyrimidines, thymidines, nucleosides and nucleotides have also been investigated as BNCT delivery agents $[16,17,41]$, in particularly 3 carboranyl thymidines (3CTAs). For example, the thymidine derivative designated $\mathrm{N} 5-2 \mathrm{OH}$ displays selective tumor uptake, a high rate of phosphorylation and low toxicity [16]. Convection enhanced delivery (CED) of $\mathrm{N} 5-2 \mathrm{OH}$ to rats bearing intracerebral RG2 gliomas has been effective for the selective delivery of therapeutic concentrations of boron to tumors with very high tumor:brain and tumor:blood ratios without any concomitant toxicity [17].

Boron-containing porphyrin derivatives (porphyrins, chlorins, bacteriochlorins, tetrabenzoporphyrins, and phthalocyanines) have been extensively investigated due to their usually low toxicity and natural affinity for tumors $[19,20]$. Examples of such compounds are BOPP [21], $\mathrm{CuTCPH}$, and $\mathrm{H}_{2} \mathrm{OCP}$. Porphyrin derivatives have been shown to deliver therapeutic amounts of boron to tumor bearing mice and rats. They attained high tumor: brain and tumor:blood boron concentration ratios, and longer retention times in tumors than BSH and BPA. In addition, boron-containing chlorins, bacteriochlorins and phthalocyanines are promising dual agents for both BNCT and photodynamic therapy (PDT) of tumors. Two of these porphyrin derivatives have been FDAapproved as photosensitizers for PDT. This is due to the strong absorptions of these macrocycles in the red and near-infrared regions of the optical spectrum, and their unique photosensitizing properties [19]. Other boroncontaining DNA binding molecules, including alkylating agents, DNA intercalators, minor-groove binders and polyamines have been investigated [34]. For example, derivatives of aziridines, acridines, phenanthridines, various $\mathrm{Pt}(\mathrm{II})$ complexes and carboranylpolyamines have been described. These compounds sometimes show low tumor selectivity and significant toxicity, in part due to their multiple cationic charges and/or ability for binding to DNA of normal cells. Boron-containing sugars, including derivatives of glucose, mannose, ribose, galactose, maltose and lactose have also been investigated [11,42]. This class of molecules usually displays low toxicity and low tumor uptake, in part due to their hydrophilicity and fast clearance from tissues.

Among the high molecular weight boron delivery agents, monoclonal antibodies (MoAbs), liposomes and nanoparticles are the most common. MoAbs are a very promising class of tumor-targeting agents due to their high specificity for molecular targets such as EGFR and VEGFR [27-30]. Extensive studies have been carried out by Barth, Wu and Yang and their co-workers using a heavily boronated precision macromolecule that has been linked by means of heterobifunctional reagents to either the EGFR targeting MoAb cetuximab (Erbitux ${ }^{\mathrm{TM}}$ ) [28], the EGFRvIII targeting MoAb L8A4 [31] or EGF itself [32]. These nanovehicles (NVs) have been administered intracerebrally (i.c.) by means of convection enhanced delivery (CED) to rats bearing receptor positive F98 gliomas, followed by BNCT $[28,29,31-33]$. The best survival data were obtained in F98 glioma bearing rats when these NVs were combined with intravenous or intra-arterial administration of BPA and BSH $[28,29,31,33]$ yielding a 2-3 fold increase in mean survival times (MST) compared to irradiated controls.

Immunoliposomes can deliver low molecular weight hydrophobic agents, such as $\mathrm{BSH}$, via incorporation into their lipid bilayers $[22,23]$. Liposomes can also transport large numbers of boronated molecules intracellularly and normally show high tumor boron uptake [24]. Hawthorne, Feakes and their co-workers have extensively investigated liposomes as BNCT delivery agents of a variety of polyhedral boron anions and these studies were recently reviewed [25]. High tumor boron concentrations were attained in vitro when polyhedral boron anions are encapsulated in tumor-selective unilamellar liposomes, but in vivo their therapeutic efficacy has yet to be demonstrated. Linkage of boron-containing liposomes to the MoAb cetuximab resulted in specific molecular targeting of the immunoliposomes to EGFR expressing F98 glioma cells [22]. Boron-containing lipids bearing covalentlybound boron clusters also have been reported. These nanoparticles have the advantages of showing no leakage of encapsulated boronated compounds, delivering high concentrations of boron to tumor-bearing mice, and increasing survival times following BNCT [26,37]. Additional classes of boron-containing nanoparticles have been investigated as BNCT delivery agents $[35,40]$ and this work has been recently reviewed [36].

\section{Neutron sources for BNCT}

As described in more detail later in this review, clinical studies on BNCT originated at the Brookhaven National Laboratory (BNL) and the Massachusetts Institute of Technology (MIT) in collaboration with the Massachusetts General Hospital (MGH) approximately 60 years ago [2]. The initial trials for the treatment of high grade gliomas were carried out with fission reactor-produced beams of thermal neutrons. The inadequate penetration of tissue by thermal neutrons, $3-4 \mathrm{~cm}$, led the clinical team in the MIT/Harvard trials to introduce intra-operative, open cranium irradiations with an air-filled balloon inserted into the surgical cavity to increase neutron penetration and avoid excessive dose to the scalp. After a hiatus of almost 25 years, more recent clinical trials were initiated at MIT and BNL, in the early 1990's, using for the first time higher energy neutrons in the epithermal energy range 
$(\sim 0.4 \mathrm{eV} \leq \mathrm{E} \leq 10 \mathrm{keV})$. These higher energy neutrons obviated the need for intra-operative BNCT when treating deep seated malignancies. Epithermal neutrons, for example, can reach tumors at the midline of the brain at a depth of $\sim 8 \mathrm{~cm}$ with therapeutic ratios $>1$. Epithermal neutrons are now generally used in BNCT irradiations although some intra-operative irradiations with thermal neutrons are still performed. Reactor-based facilities in Japan are capable of producing various mixtures of thermal and epithermal neutron spectra, which can be advantageous for head and neck cancers where deep beam penetration may not be required.

\section{Fission reactor sources for NCT}

The general characteristics of neutron beams for NCT are described in detail elsewhere [43] and the requirements for a facility capable of high patient through-put have been discussed by Harling [44]. Two approaches have been used for the design of epithermal neutron irradiation facilities at fission reactors. Direct use of the core neutrons as the source has been the predominant approach for modification or conversion of existing reactors for NCT. More than eight such facilities have been constructed for clinical use in the Americas, Europe and Asia and several more are under construction. Performance characteristics for many of these facilities have been summarized in a review by Harling and Riley [45]. An interesting new facility, which makes direct use of core neutrons from a low power reactor, was recently constructed in China and is located in a suburb of Beijing $[46,47]$. This is the first reactor designed specifically for NCT and is based on an ultra-safe, low cost design specially suited for urban populated areas or within a hospital.

Another approach to using fission reactors is based upon the use of a fission converter which converts a reactor's thermal neutrons to higher energy fission neutrons. The fission neutrons are then moderated and filtered to produce epithermal neutron beams. This approach can be especially useful to modify existing multipurpose reactors. One fission converter based facility, called the FCB (Figure 1) has been constructed at the MIT Research Reactor (MITR) $[48,49]$. The MIT FCB represents the current state of the art for epithermal neutron irradiation facilities. It meets all requirements for an epithermal neutron irradiation facility needed for routine high throughput clinical NCT. Features and capabilities of the MIT FCB include high intensity, 10-15 minutes to deliver a tolerance dose per irradiation field, accurate delivery of the prescribed neutron fluence, low beam contamination from adventitious radiation components and easy beam positioning on any part of the body. Therapeutic ratios above unity are achieved for depths up to $10 \mathrm{~cm}$ using the currently available drug, BPA.

Unless BNCT becomes more broadly accepted as a treatment modality for specific cancers, the need to develop additional nuclear reactors remains limited and further construction seems unlikely. New, special purpose reactors like the one in China, which is still not in clinical use, are a possible source of additional neutron irradiation facilities. Additional reactor conversions and modifications also can be undertaken using proven approaches that require very little research and development effort.

\section{Accelerator based neutron sources (ABNSs)}

To date, all BNCT clinical irradiations have used fission reactor neutron sources, however accelerator based neutron sources are under development and may eventually provide another option to fission reactors. Accelerator based neutron sources are being developed for use in NCT with the anticipation of being easier to site in hospitals and license than a dedicated nuclear reactor. Proponents of accelerators also believe that they could be more compact and less expensive than comparable reactor sources. ABNSs for BNCT have been reviewed in detail elsewhere $[50,51]$. Generally they produce low intensity neutron fluxes compared to reactor sources and this has been a problem for implementation. An increase in intensity by more than an order of magnitude would be necessary if accelerators are to be competitive with the better reactor sources for clinical BNCT. An ABNS recently has been constructed by Sumitomo Heavy Industries and approval for clinical use has been granted by the Pharmaceutical and Medical Safety Bureau of the Japanese Ministry of Health, Labour, and Welfare [52]. It is anticipated that clinical trials will be initiated in 2013 using this ABNS. Finally, an $8 \mathrm{MeV}, 10 \mathrm{~mA}$ linac system is under construction and this should be completed in two years (A. Matsumura, Personal Communication).

\section{Clinical dosimetry and treatment planning}

Clinical studies in BNCT have thus far been run usually as single cohorts of patients at individual centers spread across the world. These consisted mainly of Phase I/II trials to establish normal tissue tolerance and secondarily to demonstrate some possible therapeutic efficacy. Each center has, by necessity, developed their own methods to measure, calculate and prescribe absorbed doses for these trials through their own extramural research programs, and this limits their applicability to the local center where they were obtained. After more than 50 years, BNCT still remains, for the most part, an experimental modality with no standardized methods for either calibrating the mixed radiation fields employed or for calculating treatment plans that specify the patient prescription. This lack of uniformity hinders comparison of clinical results from different centers because it precludes combining or sharing clinical data on safety and efficacy in any meaningful way, which should be addressed if BNCT is to have a larger clinical role. 


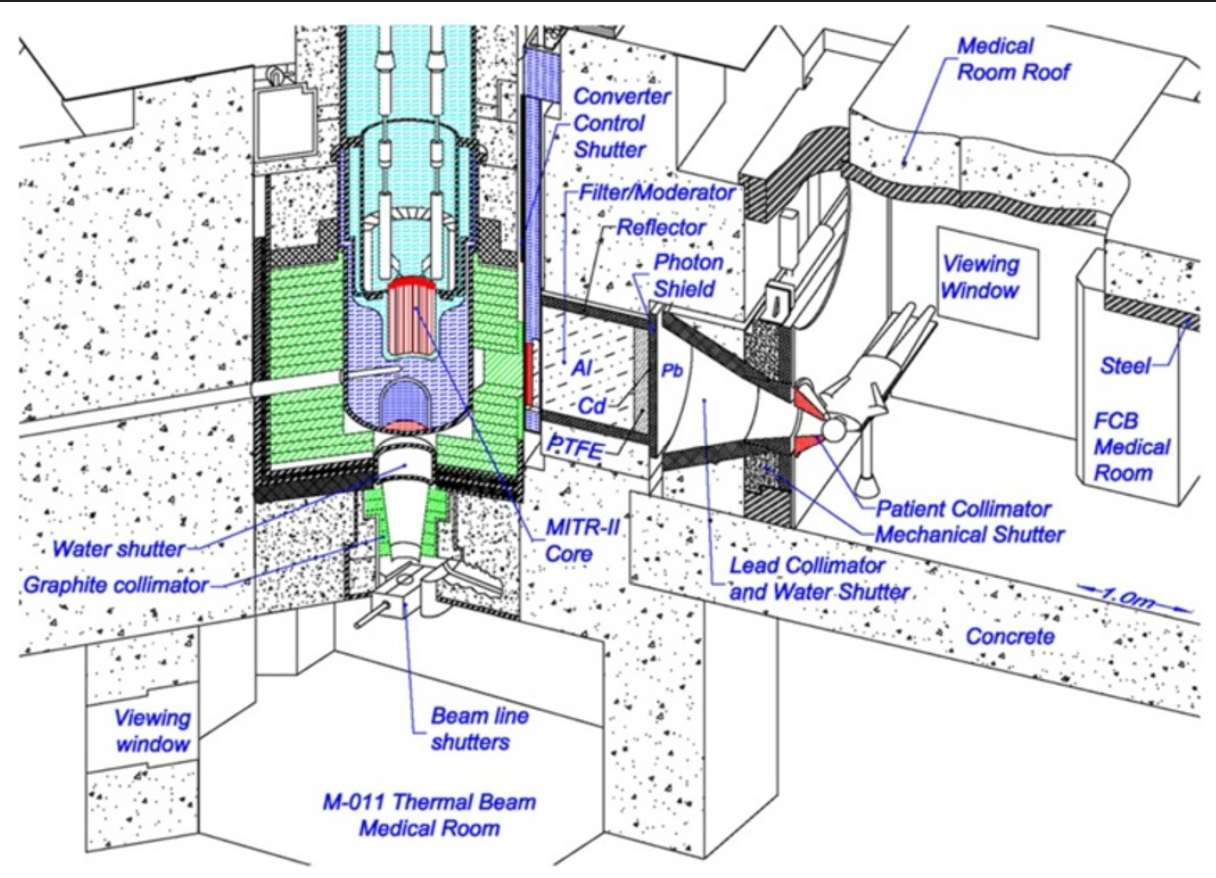

Figure 1 Schematic diagram of the Massachusetts Institute of Technology Reactor (MITR). The fission converter based epithermal neutron irradiation (FCB) facility is housed in the experimental hall of the MITR and operates in parallel with other user applications. The FCB contains an array of 11 MITR-II fuel elements cooled by forced convection of heavy water coolant. The converter power is $120 \mathrm{~kW}$ at $6 \mathrm{MW}$ reactor power. A shielded horizontal beam line contains an aluminum and Teflon ${ }^{\circledR}$ filter-moderator to tailor the neutron energy spectrum into the desired epithermal energy range. A patient collimator defines the beam aperture and extends into the shielded medical room to provide circular apertures ranging from 16 to $8 \mathrm{~cm}$ in diameter. The in-air epithermal flux is $6.2 \times 10^{9} \mathrm{n} / \mathrm{cm}^{2} \mathrm{~s}$ at the patient position with the $12 \mathrm{~cm}$ collimator. The measured specific absorbed doses are constant for all field sizes and are well below the inherent background of $2.8 \times 10^{-12} \mathrm{~Gy}_{\mathrm{w}} \mathrm{cm}^{2} / \mathrm{n}$ produced by epithermal neutrons in tissue. The dose distributions achieved with the FCB approach the theoretical optimum for BNCT. This facility is useful for clinical studies of superficial cancers and small animal studies.

The dosimetry of epithermal neutron beams is complicated by the presence of photon and fast neutron dose components in the radiation field, each possessing a markedly different biological effectiveness that must be quantified separately. In order to account for the varying biological effectiveness of the dose components, multiplicative weighting factors have been applied to the individual dose components to allow expression of their sum as a single, total weighted dose (expressed as $\mathrm{Gy}_{\mathrm{w}}$ ), which is approximately equivalent in effect to the same dose of photon radiation. These weighting factors generally have been RBE (relative biological effectiveness) factors measured in animal models [53]. A few common dosimetric methods have been developed to determine the principal absorbed dose components contributed by boron and other low energy neutron capture reactions with normal tissue hydrogen and nitrogen. These dose components generally are determined from absolute measurements of the thermal neutron flux obtained by neutron activation analysis of bare and cadmium-covered gold foils $[54,55]$. Gamma rays emitted by the activated foils are counted using a gamma spectrometer incorporating either a high-purity germanium or sodium iodide detector with a calibration traceable to a national standards laboratory. The measured thermal neutron flux is multiplied by the appropriate kerma coefficient for a given reaction and the assumed weight fraction of boron (or nitrogen) in the tissue that is being irradiated. Similarly, the twin ionization chamber technique [56], developed for fast neutron therapy [57], is often applied as the method of choice for assessing the adventitious dose arising from both the incident and induced photons as well as fast neutrons contaminating low energy neutron beams. Pairs of detectors are employed with different sensitivities to the two radiation types such as A-150 tissue equivalent plastic- and graphite- (or magnesium-) walled ionization chambers.

Treatment planning for NCT differs markedly from that of conventional radiotherapy and in some ways it is significantly more complex, requiring specialized software [58-61]. NCT treatment planning systems rely exclusively on Monte Carlo simulations for dose calculations because of the complex, scatter-dominated nature of neutron transport. The Monte Carlo method simulates transport of neutrons and photons through the patient's geometry and uses track-length density estimators of neutron and photon flux integrated against energy-dependent kerma coefficients to compute dose. Treatment planning systems require careful validation by evaluating agreement 
between dose calculations and in-phantom measurements $[62,63]$. Treatment planning calculations use individualized computational models of the target, constructed from CT or MR images. While electron density is the principal consideration for transport of megavoltage photon beams in tissue, neutron transport is governed by nuclear interactions. Since neutron cross sections vary significantly between elements, NCT dose calculations must model the elemental compositions of different tissue types in the region of interest. Concentrations of hydrogen, nitrogen, and boron have the most influence on neutron transport and dosimetry.

BNCT treatment plans are typically presented as total weighted doses, as shown in Figure 2 for tumor and normal tissue(s) and each is calculated separately for the entire dose grid using boron concentrations and weighting factors (RBEs) assumed for each tissue. The rationale for this approach is that the exact boundary of the tumor is unknown and that microscopic deposits of tumor extend well beyond the enhancing volume detectable by imaging. Generally, the tumor and tissue boron concentrations used for dose calculations in treatment planning are assessed as the product of blood boron concentrations measured for the patient at the time of irradiation and static tissue:blood boron concentration ratios determined in previous studies. For example, with BPA-fructose (BPA-F) common assumptions for tissue: blood boron concentration for tumor, normal brain, and
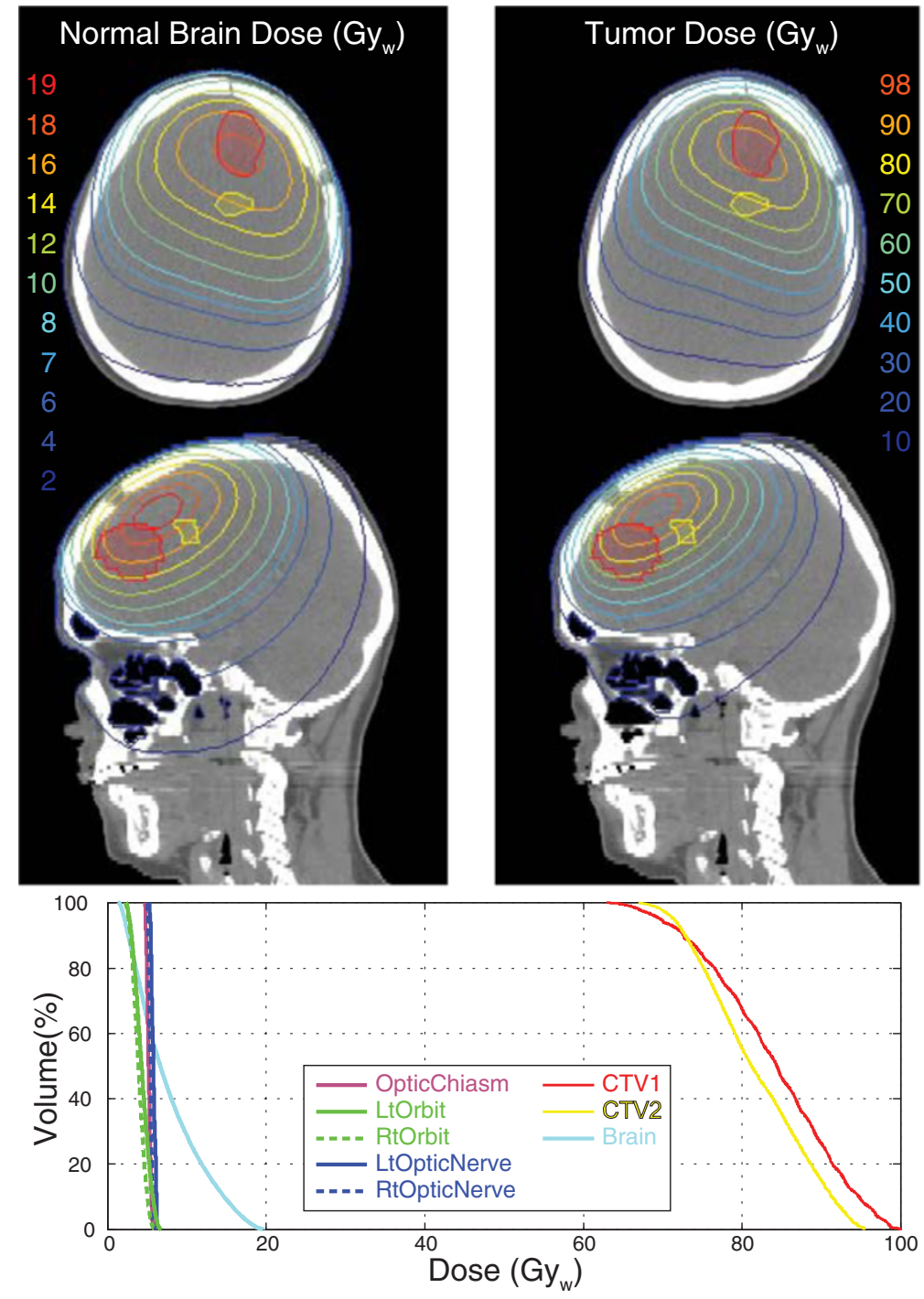

Figure 2 A three-field treatment plan for a brain tumor (GBM) patient calculated using the MiMMC treatment planning system. The prescription is a mean brain dose of $7.7 \mathrm{~Gy}$. Isodose contours calculated for tumor and normal brain are shown on axial and sagittal slices through the target volumes. The integral dose volume histograms (DVHs) summarize dosimetry for structures of interest including target volumes and organs at risk. 
skin are $3.5,1.0$, and 1.5. However, as shown in Figures 3 and 4 , in cases where $\left[{ }^{18} \mathrm{~F}\right] \mathrm{BPA}-\mathrm{F}$ PET scans [64] are available, these data often are incorporated into the treatment plan and used to estimate the spatial distribution of boron in dose calculations. Application of $\left[{ }^{18} \mathrm{~F}\right]$ BPA-F PET data to dosimetry must, however, be interpreted with caution because of considerations such as the low spatial resolution and volume averaging effects of the PET scan as well as differences between the bolus injection of radiotracer and the large volume infusion of BPA-F that occurs over an extended time for treatment.

Although most BNCT centers use some variant of these dosimetry and treatment planning methods, it is important to recognize that while the individual centers achieve satisfactory consistency or precision within particular patient cohorts, dose specifications vary considerably in absolute terms between centers. An extensive series of comparisons was performed between all clinical centers in the Americas and Europe [63,66-69] that found variations ranging between 7.6 and 13.2 $\mathrm{Gy}_{\mathrm{w}}$ for a common dose specification of $10 \mathrm{~Gy}_{\mathrm{w}}$ as defined in the Harvard-MIT clinical trials. The magnitude and range of these variations, illustrated in Figure 5 for several facilities, cannot be fully explained by experimental uncertainties or measurement errors. These variations exclude possible systematic differences related to biological weighting factors. Rather, these findings highlight specific implementation problems such as beam source definitions [70] or inexact benchmarking of treatment planning systems [62,71] that only become apparent when comparing between centers. The infrastructure and expense associated with founding and running trials has to date been significant, but even larger and more definitive patient trials are still needed to conclusively demonstrate efficacy, especially in patients with high grade gliomas. This is likely beyond the means of any single center and will only be possible through collaborative clinical trials run by multiple institutions. As a prerequisite, the NCT research community needs to recognize the importance of quantifying and establishing dose uniformity between centers and prioritize these endeavors if larger multi center trials are to succeed.

\section{Clinical studies of BNCT for brain tumors utilizing thermal neutron beams}

The clinical potential of BNCT first was recognized by Locher [72] shortly after the discovery of the neutron. However, it was not until 1951 that the first clinical trials were initiated by Sweet at the Massachusetts General Hospital (MGH) and Brownell at MIT [73] and Farr at the Brookhaven National Laboratory (BNL) in New York [74] using sodium tetraborate (borax), sodium pentaborate, $p$-carboxyphenylboronic acid, or sodium decahydrodecaborate $\left(\mathrm{Na}_{2} \mathrm{~B}_{10} \mathrm{H}_{10}\right)$ as the sole boron delivery agent. However, since these studies utilized thermal neutron beams they will not be discussed here. Interested readers are referred to a comprehensive review describing these studies in detail [2], as well as reports by Farr

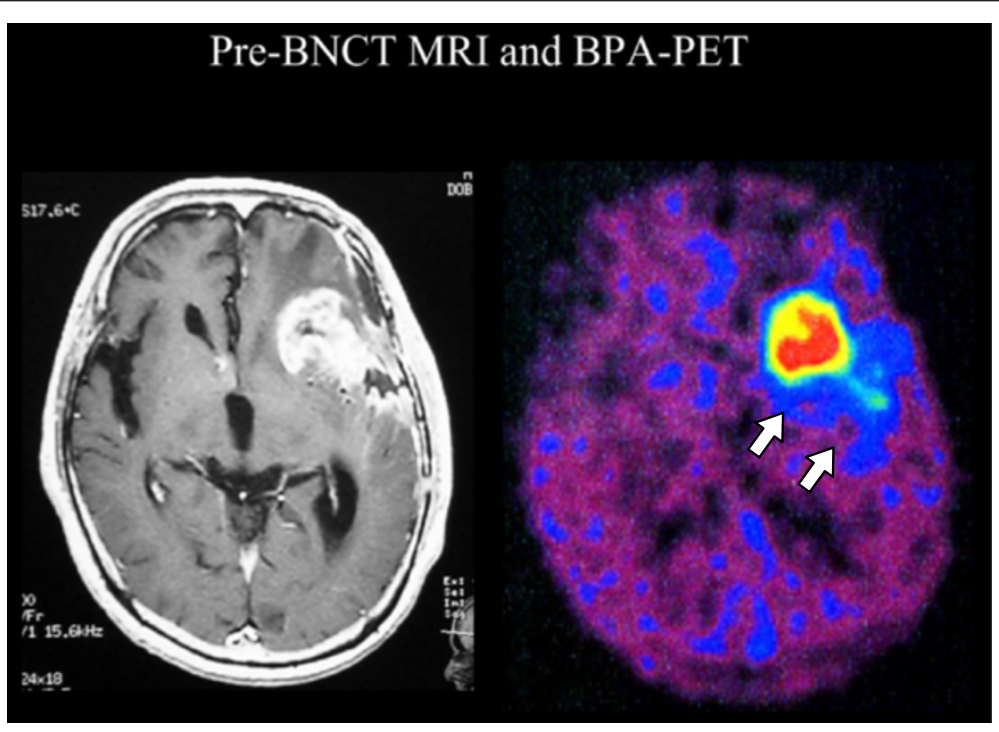

Figure 3 Contrast-enhanced T1-weighted MRI of representative glioblastoma patient and ${ }^{18}$ F-labeled BPA-PET image after initial debulking surgery. The patients received ${ }^{18} \mathrm{~F}$-BPA-PET to assess the distribution of BPA and to estimate the boron concentration in tumors before $B N C T$ without direct determination of boron concentration in the tumor. The lesion to normal brain $(L / N)$ ratio of the enhanced tumor was 7.8 in this case. Note that even the periphery of the main mass, i.e., the infiltrative portion of the tumor, showed BPA uptake. The L/N ratio of BPA uptake can be estimated from this study and dose planning was done according to this $\mathrm{L} / \mathrm{N}$ ratio, and if the $\mathrm{L} / \mathrm{N}$ ratio was more than 2.5 , then BNCT was initiated. ${ }^{18}$ F-BPA-PET accurate BPA provided an accurate estimate of the accumulation and distribution of BPA as previously reported $[64,65]$. 

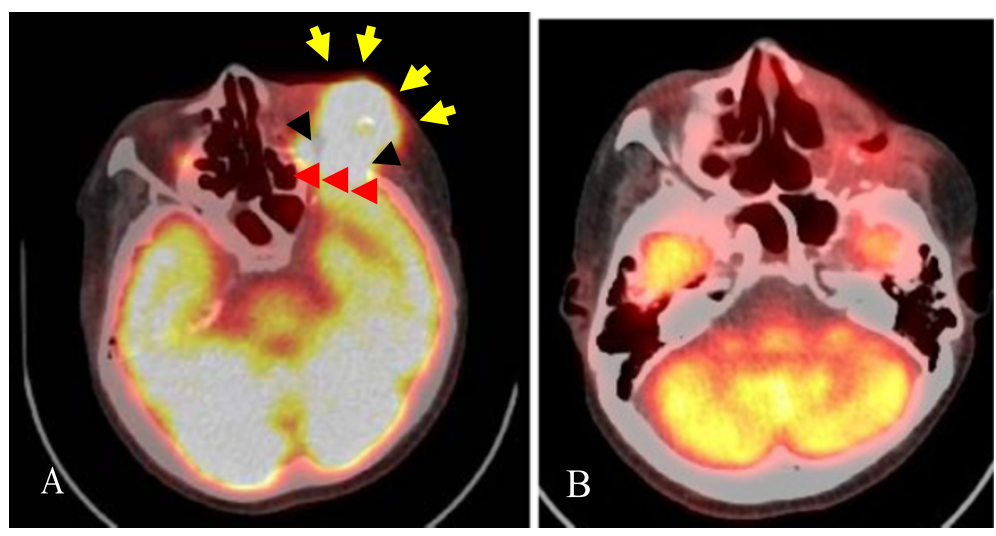

Figure $4{ }^{18}$ FDG-PET study prior and 6 months after BNCT of a 56 year-old male patient with recurrent squamous cell carcinoma of the maxilla. A: FDG accumulated in the left orbital region (arrows) and frontal lobe of brain (arrow heads). B: No accumulation of FDG-PET was detected 6 months after BNCT and the patient was disease free for 61 months at the time of the original report. Photographs are from Applied Radiation and Isotopes, 67:S37-S42, 2009.

[74] and Asbury [75] and their co-workers. Similarly, Hatanaka [76] and later Hatanaka and Nakagawa [77] carried out extensive studies in Japan using BSH as the boron delivery agent [78]. Again these studies also used thermal neutron beams, and therefore they will not be discussed in the present review. However, interested readers are referred to articles of Hatanaka [76] and Nakagawa [77], as well as those of other Japanese neurosurgeons who utilized thermal neutron beams.

\section{Clinical trials carried out in the United States}

Clinical trials were again initiated in the United States utilizing epithermal neutron beams in the 1990s when BNCT was resumed at the BNL Medical Research Reactor (BMRR) $[79,80]$ and at Harvard-MIT using the MITR [81]. In a major step forward, BPA was used as the boron delivery agent and, for the first time, patients were irradiated with a collimated beam of higher energy epithermal neutrons in two fractions on consecutive days. These had greater tissue-penetrating properties than thermal neutrons and were well tolerated. These trials benefited from a number of other technological developments that occurred over the intervening decades: Monte Carlo treatment planning and dosimetry based on tomographic imaging, accurate physical dosimetry techniques, rapid and reliable boron analysis techniques, and an improved understanding of the radiobiology of BNCT. The median survival times of patients that had received a single treatment with BNCT were equivalent to those receiving conventional, fractionated radiation therapy $[80,81]$. Furthermore, these trials established the safety of the new procedure and this set the stage for the use of BPA in combination with epithermal neutrons as the new standard. This subsequently was adopted by clinicians in Japan and Finland for the treatment of patients with high grade gliomas.
Worldwide clinical experience using BNCT with epithermal neutrons to treat high grade gliomas and other brain tumors is summarized in Tables 2 and 3.

\section{Clinical trials in Japan}

Kawabata and Miyatake and their clinical team have carried out several studies in which either BPA alone or in combination with BSH have been used for BNCT [101-103,106]. The patients had either primary, surgically resected gliomas or recurrent GBMs who had previously received X-irradiation. Favorable responses were seen in patients with newly diagnosed GBMs, especially those in high risk groups [102], using BPA and BSH either with or without an X-ray boost. Patients treated with surgery and BNCT using $100 \mathrm{mg} / \mathrm{kg} \mathrm{BSH}$ infused over $1 \mathrm{~h}$ and $700 \mathrm{mg} / \mathrm{kg}$ BPA infused over $6 \mathrm{~h}$ followed by 20-30 Gy of fractionated $\mathrm{X}$-rays (Protocol 2) had a median survival time (MeST) of 23.5 months compared to 14.1 mos. for those who had surgery followed by BNCT using $100 \mathrm{mg} / \mathrm{kg} \mathrm{BSH}$ and a lower dose of BPA, $250 \mathrm{mg} / \mathrm{kg}$ infused over $1 \mathrm{~h}$ (protocol 1) (Figure 6). The composite MeST of patients who had surgery and BNCT (with or without X-rays) $(\mathrm{n}=21)$, was 15.6 mos. (95\% confidence interval $(\mathrm{CI})$ : 12.2-23.9 mos. This was significantly longer than 10.3 mos. for historical controls $(n=27)$ at the Osaka Medical College who had surgery followed by radiation therapy and chemotherapy with ACNU [106]. These clinical studies have validated the animal model data of Barth et al. showing an increase in MSTs of F98 glioma bearing rats by combining BNCT with X-irradiation [107]. Predicting which patients might be more likely to respond to BNCT would be a major step forward. Fluorine-18 labeled BPA has been used to predict the effectiveness of BNCT $[64,65]$, as well as to detect post treatment radiation effects [65]. Representative radiographic changes seen in 


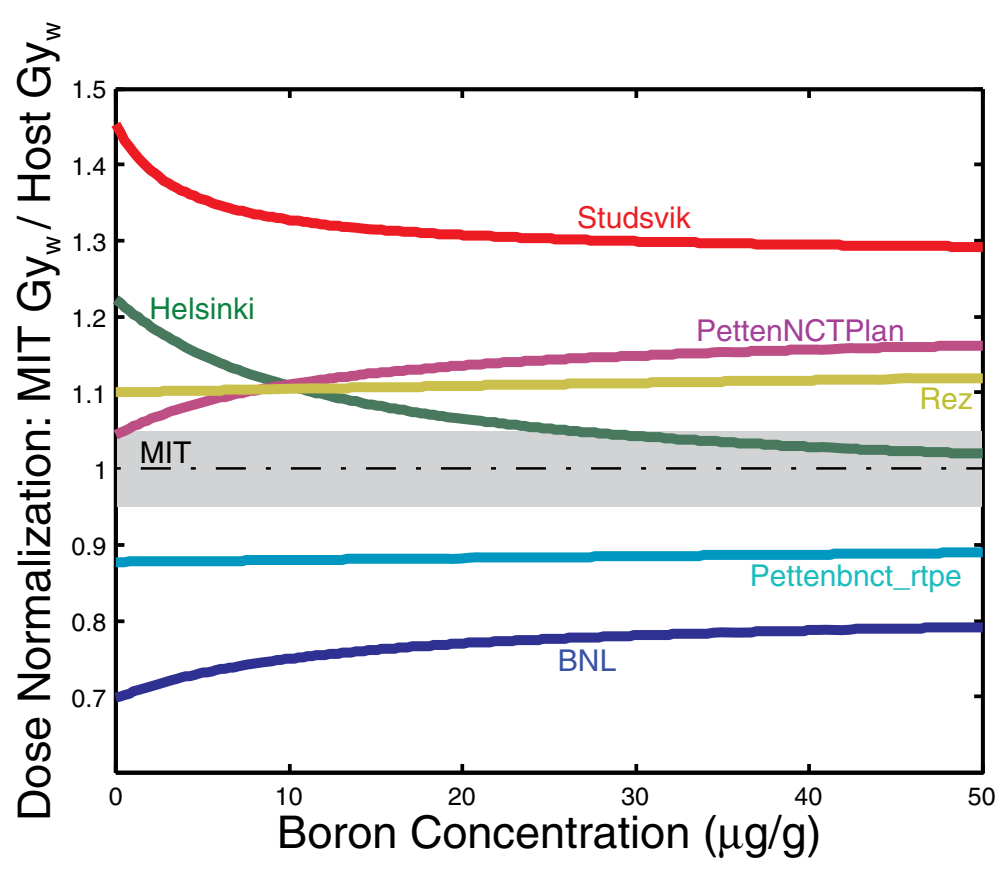

Figure 5 Graphical representation of a parameterized model converting the maximum weighted dose, calculated Treatment Planning System (TPSs) from each center to an MIT calibrated dose as a function of boron uptake in tissue [69]. The plotted curves afford an easy and direct comparison of dose specification between participants of the International Dosimetry Exchange.

two patients, treated by BNCT, are shown in Figure 7 and PET imaging studies with ${ }^{18} \mathrm{~F}$-BPA are shown in Figure 3. Although retrospective comparisons must be interpreted with caution, the MeST from the date of diagnosis, calculated using the Kaplan-Meier method (Figure 6), for historical controls was 10.3 months (95\% CI: 7.4-13.2, logrank test $\mathrm{p}=0.0035)$ compared to 23.5 months $(95 \% \mathrm{CI}$ : 10. 2 mos. to undetermined) after diagnosis $(n=11)$, for patients treated with BNCT plus X-irradiation. However, the MeST of patients in Protocol 1 (BNCT-XRT) was 14.1 months (95\% CI: 9.9 mos.-18.5 mos.), which was not significantly different from historical controls, but this may be attributable to low patient numbers since they were subdivided into two protocols involving only 10 and 11 patients each. Kawabata, Miyatake and their co-workers plan to evaluate BNCT in combination with temozolomide in a multicenter Phase II Japanese clinical study (OSAKA-TRIBRAIN0902, NCT00974987). Finally, extensive studies also have been carried out by Matsumura and his clinical team at the University Hospital of Tsukuba [108-110] using either BPA or BSH alone or in combination as the boron delivery agents (see Table 3). In some cases BNCT was combined with a photon boost in combination with temozolomide in patients with either primary or recurrent GBMs. The approach used mosst recently at the University of Tsukuba, using BPA in combination with $\mathrm{BSH}$, followed by a fractionated photon boost, has resulted in the most favorable survival achieved with BNCT to date: 27.1 mos. MeST with a 2 year OS of $63 \%(n=8)[109,110]$. However, these results must be interpreted, with caution due to the very small number of patients that have been treated. A randomized Phase II clinical trial with a sufficient number of patients will be required to validate these very encouraging but preliminary results.

\section{Clinical studies in Finland}

Kankaanranta et al. at the Helsinki University Central Hospital and VTT Technical Research Center of Finland have reported on 22 patients with GBMs who had undergone standard therapy, recurred, and subsequently received $\mathrm{BNCT}$ at the time of their recurrence using BPA as the boron delivery agent [88]. The overall MeST was 7 mos. and the median time to progression was 3 mos. However, it is difficult to compare these survival data and those reported for patients with recurrent GBMs receiving conventional treatments. Nevertheless, they are a starting point for future studies using BNCT as salvage therapy in patients with recurrent tumors.

\section{EORTC clinical study}

APhase I clinical trial was carried out by the European Organization for Research and Treatment of Cancer to evaluate BSH as a boron delivery agent (protocol \#11961) using the High Flux Reactor at Petten, the Netherlands. The aims of this study were to investigate the systemic 
Table 2 BNCT clinical trials in the United States and Europe using epithermal neutron beams for patients with brain tumors

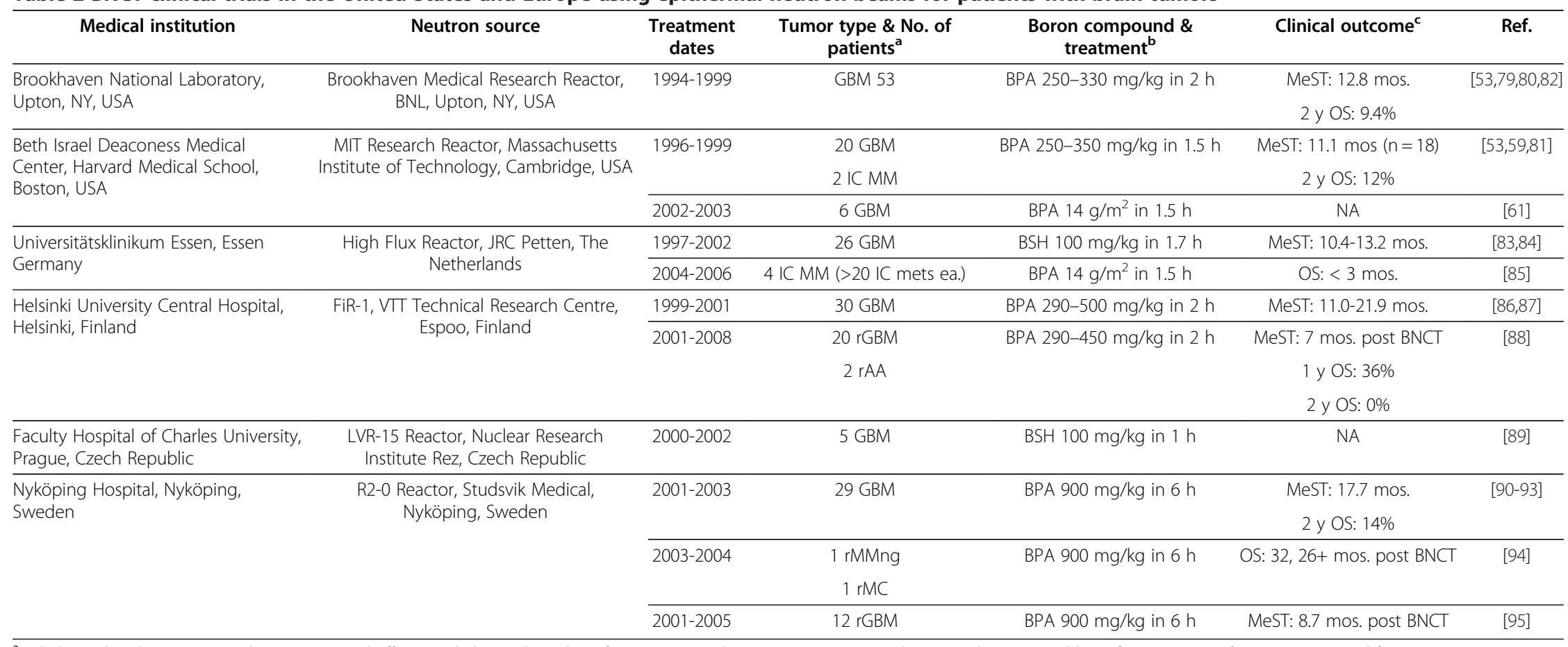

Including other disease sites and patients treated off-protocol, the total number of patients treated at some reactors is much greater than reported here, for FiR-1, 260, for KURR, >107, and for JRR-4, >200 patients. ${ }^{\mathrm{b}}$ Treatment is indicated only in cases when it is not solely external beam BNCT. ${ }^{\mathrm{C}} \mathrm{A}$ range of survival is given in some cases to summarize survival reported for different cohorts.

Abbreviations: $r$ recurrent, GBM glioblastoma multiforme, IC MM intracranial metastatic melanoma, AA anaplastic astrocytoma, MMng malignant meningioma, $M C$ mesenchymal chondrosarcoma, AOA anaplastic

oligoastrocytoma, MRM meningioma related malignancy, IO-BNCT intraoperative BNCT, XRT external beam radiation therapy (photons), MeST median survival time, 2 y OS 2 year overall survival, RI radiographic improvement, NA not available. 


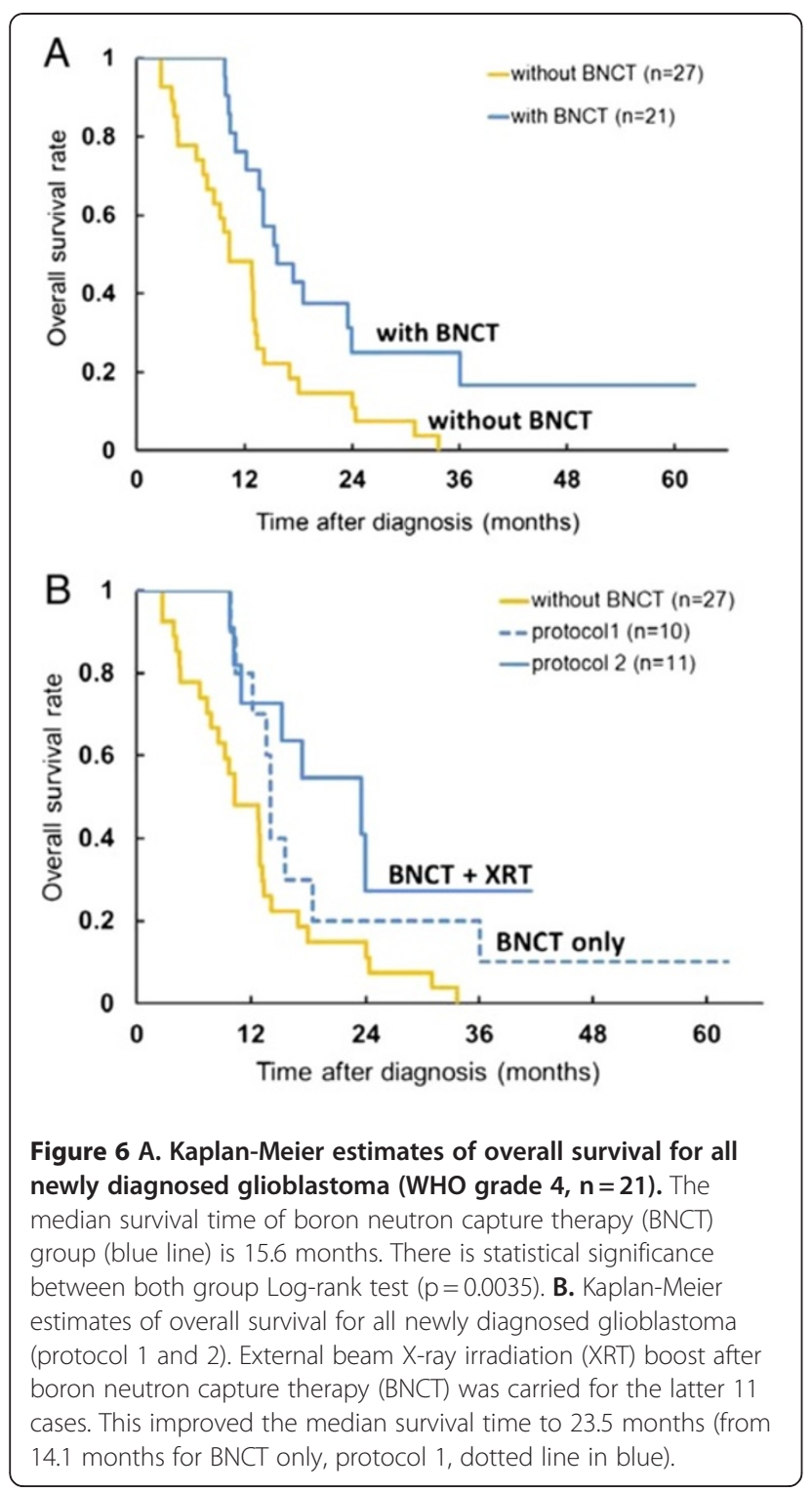

toxicity of i.v. administration of BSH, the maximum tolerated radiation dose and the dose limiting toxicity of BNCT. At the time of reporting [83,84] a total of 26 patients had been treated with BNCT with a starting dose of $8.6 \mathrm{~Gy}$. In all but one patient, BNCT was performed in 4 fractions on 4 consecutive days. On the day prior to the first irradiation BSH $(100 \mathrm{mg} / \mathrm{kg}$ b.w.) was administered i.v. Both the amount administered and the time from BSH infusion to irradiation (range 8-14 h) were adjusted to achieve a blood boron concentration of $\sim 30 \mu \mathrm{g} / \mathrm{g}$ during irradiation. The MeST of the first patient group was 10.4 months after the first surgery, 11.3 months for the second group and 13.2 months for the third patient group [83]. However, dose limiting toxicities were observed in this study [84].These mainly consisted of cerebral atrophy and white matter abnormalities [84].

\section{Clinical studies in Sweden}

We would like to conclude this section on BNCT of high grade gliomas with a summary of a clinical trial that was carried out in Sweden using BPA and an epithermal neutron beam. This study differed significantly from all previous clinical trials in that the total amount of BPA infused was increased to $900 \mathrm{mg} / \mathrm{kg} \quad$ b.w., and it was given i.v. over 6 hours [90]. This regimen was based on animal studies in F98 glioma bearing rats that showed that boron concentrations in invading tumor cells increased from $37 \%$ to $71 \%$ of that in the main tumor if the infusion time was increased from $2 \mathrm{~h}$ to $6 \mathrm{~h}$ [111]. The higher dose and longer infusion time of the BPA were well tolerated by the 29 patients who were enrolled in this study [90-93,112]. The minimum dose to the tumor ranged from 15.4 to $54.3 \mathrm{~Gy}_{\mathrm{w}}$ and the mean weighted dose to whole brain was 3.2-6.1 $\mathrm{Gy}_{\mathrm{w}}$ and all were treated with 2 fields. There has been some disagreement among the Swedish investigators who carried out this study on evaluation of the results. One group reported survival data that was compiled before all of the patients had succumbed to their tumors [91]. Based on all of the survival data, another group [92,93,112] determined that the MeST was 17.7 mos. compared to 15.5 mos. for patients who received standard therapy of surgery, followed by radiotherapy (RT) and temozolomide. Furthermore, the frequency of adverse events were lower after BNCT (14\%) than after RT alone (21\%) and both of these were lower than those seen following RT in combination with temozolomide. If these improved survival data, using a 6-hour infusion time and a higher dose of BPA, can be confirmed by others, preferably in a randomized clinical trial, it could represent a significant step forward in BNCT of brain tumors, especially if combined with a photon boost.

\section{Clinical studies of BNCT for head and neck cancer Studies carried out in Japan}

The use of BNCT to treat patients with recurrent cancers of the head and neck region who had failed all other therapies was first initiated in 2001 by Kato and his co-workers in Japan [5] at the Kyoto University Research Reactor Institute (KURRI). The rationale for this was based on the ability of BNCT to deliver a large additional dose of radiation to the site of the tumor with a sparing of contiguous normal tissues. The first patient treated had a recurrent mucoepidermoid carcinoma of the parotid gland. Locoregional control was achieved and she died 7 years later of unrelated disease (Figure 8). Similar, clinically impressive results were seen in other patients treated by Kato et al. [5] and ${ }^{18} \mathrm{~F}$-BPA and ${ }^{18} \mathrm{~F}$-FDG PET scans from two patients are shown in Figures 9 and 4, respectively. Kato et al. survival data are summarized in the Kaplan-Meier plots shown in Figure 10. Based on these promising results two independent clinical trials were initiated in Japan by Kato 
Table 3 BNCT clinical trials in Japan using epithermal or mixed thermal \& epithermal neutron beams for patients with brain tumors

\begin{tabular}{|c|c|c|c|c|c|c|}
\hline Medical institution & Neutron source & $\begin{array}{l}\text { Treatment } \\
\text { dates }\end{array}$ & $\begin{array}{c}\text { Tumor type \& No. of } \\
\text { patients }^{\mathrm{a}}\end{array}$ & $\begin{array}{l}\text { Boron compound \& } \\
\text { treatment }^{\mathrm{b}}\end{array}$ & Clinical outcome & Ref. \\
\hline \multirow{7}{*}{$\begin{array}{l}\text { University of Tsukuba, Tsukuba City, } \\
\text { Ibaraki, Japan }\end{array}$} & \multirow{7}{*}{$\begin{array}{c}\text { JRR-4, Japan Atomic Energy Agency, } \\
\text { Tokai, Ibaraki, Japan }\end{array}$} & \multirow[t]{2}{*}{$1999-2002$} & $5 \mathrm{GBM}$ & $\mathrm{BSH} 100 \mathrm{mg} / \mathrm{kg}$ in $1-1.5 \mathrm{~h}$ & MeST: 23.2 mos. (GBM) & \multirow[t]{2}{*}{ [96] } \\
\hline & & & $4 \mathrm{AA}$ & IO-BNCT & MeST: 25.9 mos. (AA) & \\
\hline & & \multirow[t]{2}{*}{$1998-2007$} & \multirow[t]{2}{*}{$7 \mathrm{GBM}$} & \multirow[t]{2}{*}{ BSH $5 \mathrm{~g}$ in $1 \mathrm{~h}, \mathrm{IO}-\mathrm{BNCT}$} & MeST: 23.3 mos. & \multirow[t]{2}{*}{ [97] } \\
\hline & & & & & 2 y OS: $43 \%$ & \\
\hline & & \multirow[t]{3}{*}{$1998-2007$} & \multirow[t]{3}{*}{$8 \mathrm{GBM}$} & \multirow{3}{*}{$\begin{array}{c}\text { BSH } 5 \mathrm{~g} \text { in } 1 \mathrm{~h} \& \mathrm{BPA} \\
250 \mathrm{mg} / \mathrm{kg} \text { in } 1 \mathrm{~h} \\
\mathrm{BNCT}+\mathrm{XRT}\end{array}$} & MeST: 27.1 mos. & \multirow[t]{3}{*}{ [97] } \\
\hline & & & & & 2 y OS: $63 \%$ & \\
\hline & & & & & & \\
\hline \multirow{7}{*}{$\begin{array}{l}\text { University of Tokushima, Tokushima, } \\
\text { Japan }\end{array}$} & \multirow{7}{*}{$\begin{array}{c}\text { JRR-4 or KURR (Kyoto University Research } \\
\text { Reactor, Osaka, Japan) }\end{array}$} & \multirow[t]{2}{*}{$1998-2000$} & \multirow[t]{2}{*}{$6 \mathrm{GBM}$} & BSH 64.9-178.6 mg/kg & MeST: 15.5 mos. & \multirow[t]{2}{*}{ [98-100] } \\
\hline & & & & IO-BNCT & 2 y OS: $0 \%$ & \\
\hline & & \multirow[t]{2}{*}{$2001-2004$} & \multirow[t]{2}{*}{$11 \mathrm{GBM}$} & BSH 64.9-178.6 mg/kg & MeST: 19.5 mos. & \multirow[t]{2}{*}{ [98-100] } \\
\hline & & & & IO-BNCT & 2 y OS: $27 \%$ & \\
\hline & & \multirow[t]{3}{*}{$2005-2008$} & \multirow[t]{3}{*}{$6 \mathrm{GBM}$} & \multirow{3}{*}{$\begin{array}{c}\text { BSH } 100 \mathrm{mg} / \mathrm{kg} \& \mathrm{BPA} \\
250 \mathrm{mg} / \mathrm{kg} \\
\text { BNCT + XRT }\end{array}$} & MeST: 26.2 mos. & \multirow[t]{3}{*}{ [98-100] } \\
\hline & & & & & 2 y OS: $50 \%$ & \\
\hline & & & & & & \\
\hline \multirow[t]{10}{*}{ Osaka Medical College, Osaka, Japan } & \multirow[t]{10}{*}{ KURR } & \multirow[t]{2}{*}{$2002-2003$} & \multirow[t]{2}{*}{$10 \mathrm{GBM}$} & \multirow{2}{*}{$\begin{array}{c}\text { BSH } 5 \text { g \& BPA } 250 \mathrm{mg} / \mathrm{kg} \text { in } \\
1 \mathrm{~h}\end{array}$} & MeST: 14.5 mos. & \multirow[t]{2}{*}[101,102]{} \\
\hline & & & & & 2 y OS: $20 \%$ & \\
\hline & & \multirow[t]{3}{*}{$2003-2006$} & \multirow[t]{3}{*}{$11 \mathrm{GBM}$} & \multirow{3}{*}{$\begin{array}{c}\text { BSH } 5 \mathrm{~g} \& \text { BPA } 700 \mathrm{mg} / \mathrm{kg} \text { in } \\
6 \mathrm{~h} \\
\text { BNCT + XRT }\end{array}$} & MeST: 23.5 mos. & {$[102]$} \\
\hline & & & & & 2 y OS: $27.3 \%$ & \\
\hline & & & & & & \\
\hline & & 2002-2007 & 19 rGBM & $\mathrm{BSH} 100 \mathrm{mg} / \mathrm{kg} \& \mathrm{BPA}$ & MeST: 10.8 mos. post BNCT & [103] \\
\hline & & & $2 \mathrm{rAA}, 1 \mathrm{rAOA}$ & $1 \mathrm{ho}$ & 2 y OS: $14 \%$ & \\
\hline & & & & $\begin{array}{l}\text { BSH } 100 \mathrm{mg} / \mathrm{kg} \& \text { BPA } \\
700 \mathrm{mg} / \mathrm{kg} \text { in } 6 \mathrm{~h}\end{array}$ & & \\
\hline & & 2005-2006 & $7 \mathrm{rMRM}$ & $\mathrm{BSH} 0-5 \mathrm{~g}$ & Rl: $100 \%$ & {$[104,105]$} \\
\hline & & & & BPA $500-700 \mathrm{mg} / \mathrm{kg}$ in $3-4 \mathrm{~h}$ & & \\
\hline
\end{tabular}

Including other disease sites and patients treated off-protocol, the total number of patients treated at some reactors is much greater than reported here, for FiR-1, 260, for KURR, $>107$, and for JRR-4, $>200$ patients. ${ }^{b}$ Treatment is indicated only in cases when it is not solely external beam BNCT.

Abbreviations: $r$ recurrent, GBM glioblastoma multiforme, IC MM intracranial metastatic melanoma, $A A$ anaplastic astrocytoma, $M M n g$ malignant meningioma, $M C$ mesenchymal chondrosarcoma, $A O A$ anaplastic oligoastrocytoma, MRM meningioma related malignancy, IO-BNCT intraoperative BNCT, XRT external beam radiation therapy (photons), MeST median survival time, 2 y OS 2 year overall survival, RI radiographic improvement $N A$ not available. 
and Suzuki and their respective teams to evaluate the safety and efficacy of BNCT in patients with a variety of malignancies of the head and neck region and these are summarized in Figures 10 and 11 and Table 4. A total of 68 patients with either newly diagnosed or recurrent, therapeutically refractory tumors were treated by Suzuki et al. between December 2001 and September 2007 (Figure 11). $\mathrm{BPA}$ and $\mathrm{BSH}$, either alone or in combination, were used as the capture agents with either single or multiple applications of BNCT. Initially, BPA was administered i.v. at a dose of 250 or $500 \mathrm{mg} / \mathrm{kg}$ over 1-2 h, followed by BNCT using an epithermal beam within 15 min after termination of the infusion of BPA. Beginning in June 2004, BPA was infused at a dose of $500 \mathrm{mg} / \mathrm{kg}$ over $3 \mathrm{~h}$ at a rate of $200 \mathrm{mg} / \mathrm{kg} \mathrm{h}$ for the first $2 \mathrm{~h}$, and then at a rate of $100 \mathrm{mg} /$ $\mathrm{kg} \mathrm{h}$ for the final hour during which time the patient received $\mathrm{BNCT}$. For patients who had received both $\mathrm{BSH}$ and BPA, epithermal neutron irradiation was initiated $12 \mathrm{~h}$ after termination of the infusion of $\mathrm{BSH}$ and one hour after that of BPA. The duration of BNCT was adjusted so that the majority of the cases the maximum radiation dose to the surrounding skin and normal tissue would be $<10-12 \mathrm{~Gy}_{\mathrm{w}}$.

\section{Patient population and treatment results}

All of Suzuki's patients had unresectable advanced or recurrent cancers of the head and neck region. Forty-nine patients (79\%) had recurrent tumors and 13 (21\%) had newly diagnosed unresectable tumors. Among the 49 patients, 39 (80\%) had previous chemotherapy, 41 (84\%) had previous surgical resection, and 36 (73\%) had previous radiotherapy. Treatment sites included the oral and nasal cavities, paranasal sinuses and neck. Forty-two of the 62 patients received BNCT once, 17 received it twice, two received it three times, and one received it five times. Based on CT or MR imaging of 57 patients who had any target lesions, 16 showed a CR, and 17 had a PR for an overall response rate $(\mathrm{CR}+\mathrm{PR})$ of $58 \%$ at 6 months. MeST
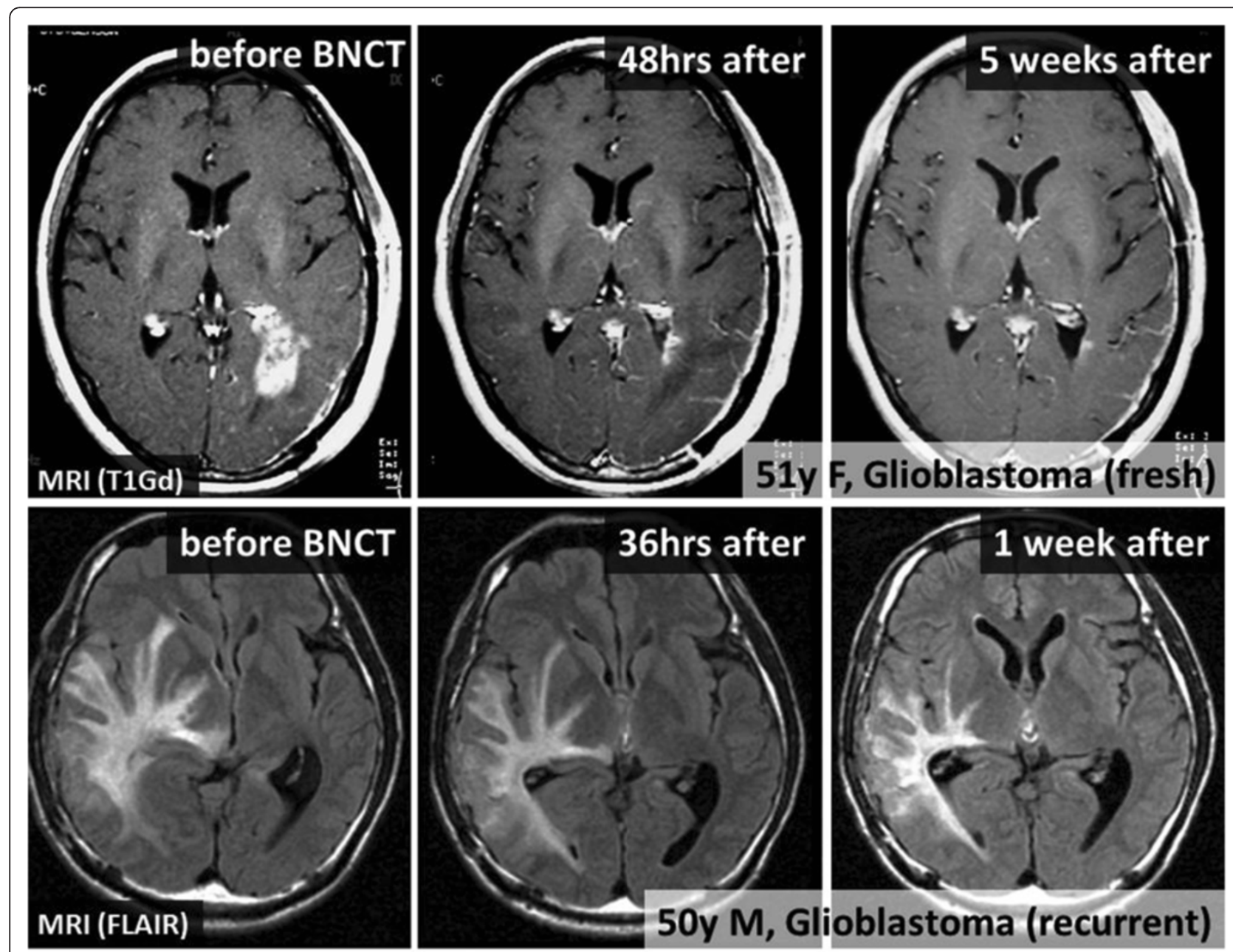

Figure 7 Radiographic changes following BNCT in two representative patients with GBM. In both, there was a reduction in both mass and peritumoral edema without the administration of corticosteroids or mannitol within a few days. This is also shown in the FLAIR image of Case \#12. 


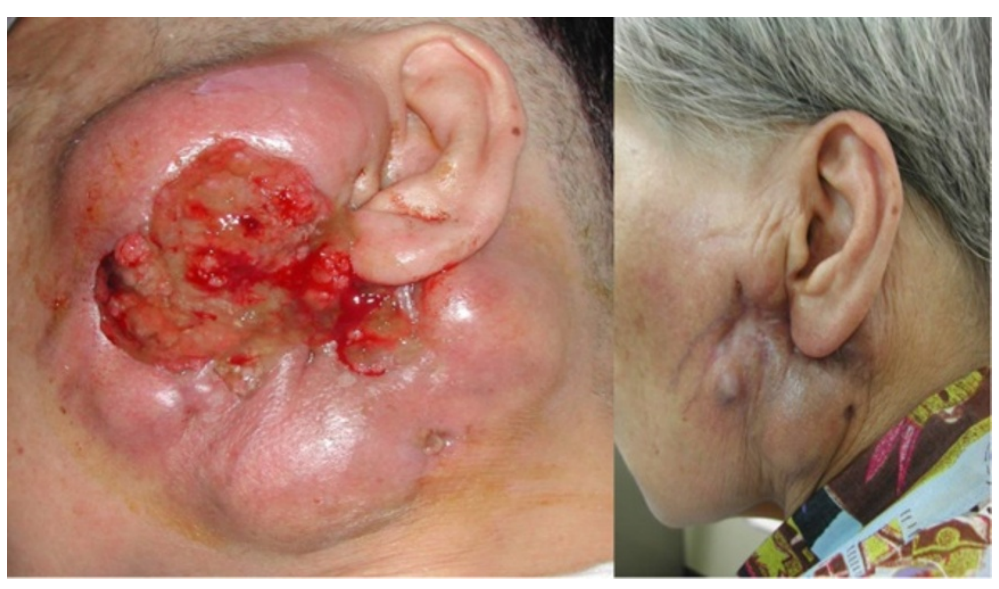

Figure 8 Before BNCT (left) and 22 months after the first BNCT (right) of a patient with a recurrent mucoepidermoid carcinoma of the parotid gland. Three treatments with BNCT produced a remarkable reduction in tumor size, but also resolution of a cutaneous ulcer and reepithelization by normal skin. These results clearly demonstrate that BNCT is a highly tumor-selective treatment modality. She lived for 7 years following treatment (Applied Radiation and Isotopes, 61:1069-1073, 2004).

of 53 evaluable patients was 10.1 months from time of BNCT, and 1- and 2- year OS rates were $43 \%$ and $24 \%$, respectively. The one year survival for newly diagnosed unresectable tumors was $58 \%$ and for those with recurrent tumors it was $41 \%$. The MeST and median progression free survival (PFS) time and 1-year PFS rate for patients with recurrent tumors were 9.7 months, 5.1 months and 5\%, respectively. The best 1-year OS was seen in 6 patients with recurrent adenocarcinomas (100\%), followed by 6 with melanoma (60\%) and in 29 with squamous cell carcinoma (26\%). The major acute grade 3 or 4 BNCT-related toxicities were hyperamylasemia, fatigue, mucositis/stomatitis and pain, all of which were manageable. The most serious complications were carotid artery hemorrhage in 3 patients, two of whom died from rupture of an infected carotid artery, which had been invaded by tumor. In summary, the overall response rate and survival rate in both studies were comparable to those obtained with chemotherapy and re-irradiation, but in the majority of patients this was accomplished in one single BNCT treatment. One significant limitation of the approach used here was that deep-seated tumors could not receive a sufficient dose due to the limited depth of penetration of epithermal neutrons and, therefore, BNCT should be limited to more shallow tumors.

\section{Study carried out in Finland}

A third clinical trial, carried out in Helsinki Finland, recently has been reported by Kankaanranta et al. [7]. A total of 30 patients with inoperable, locally recurrent cancers of the head and neck region were treated with BNCT. The majority (24 patients) had squamous cell carcinomas, and 14 of these were staged as T4, N0. They all previously

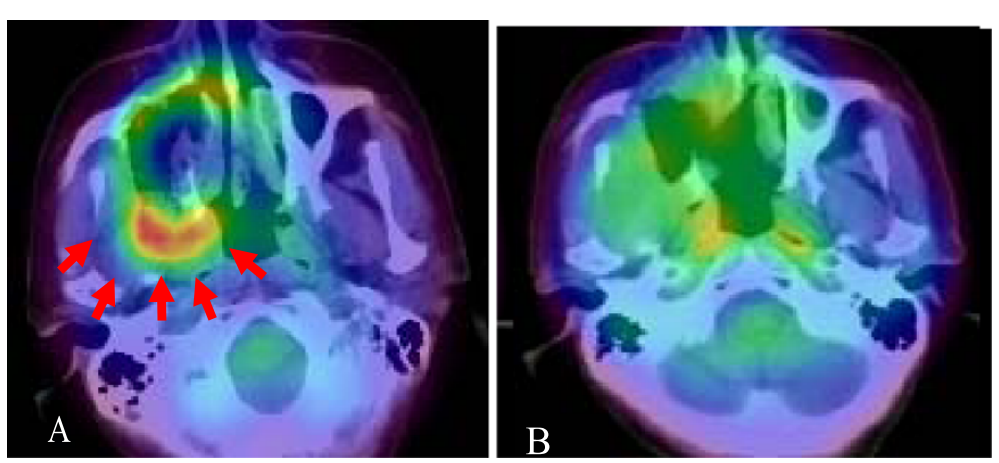

Figure $9{ }^{18} \mathrm{FBPA}$-PET study prior to and 7 months following the first BNCT treatment. A. A 61 year-old female with residual maxillary adenoid cystic carcinoma (arrows) infiltrating into pterygopalatine fossa (T4N1M0) after maxillectomy, who was treated twice with BNCT using BPA followed by chemotherapy. B. Residual maxillary cancer and a regional lymph node metastasis were no longer evident at 42 months although bilateral multiple pulmonary metastases were detected at 18 months after the first BNCT treatment. The patient lived for 59 months following BNCT (Applied Radiation and Isotopes, 67:S37-S42, 2009). 


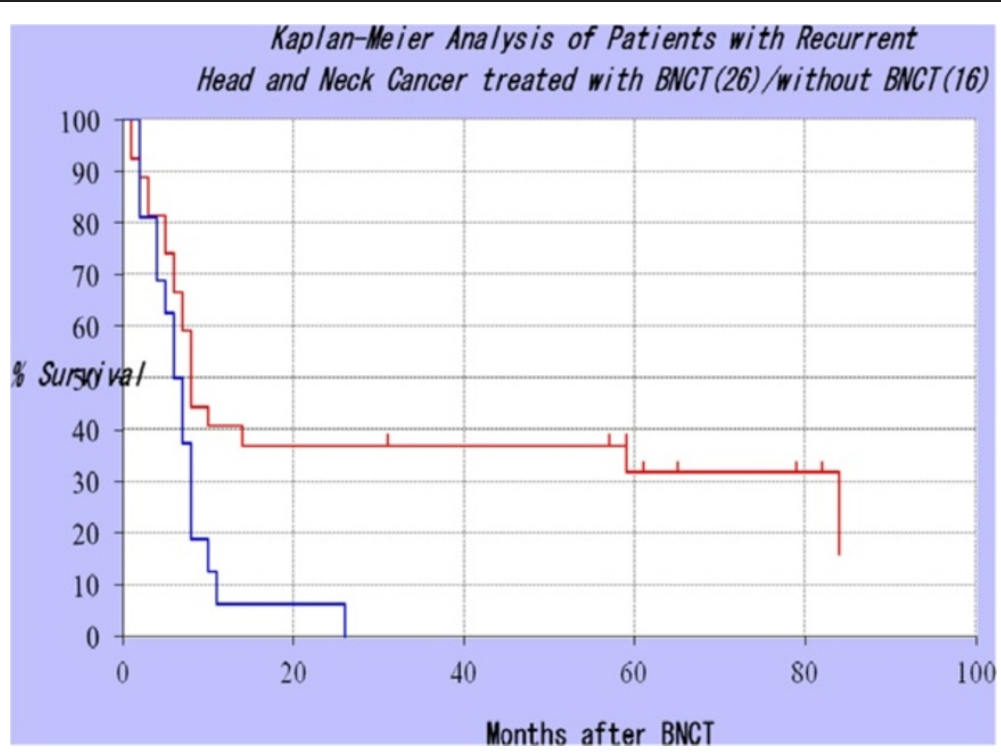

Figure 10 Kaplan-Meier survival plots of patients with recurrent HNC treated by Kato et al. (6) with BNCT (26 cases, red line) and those who treated with other than BNCT (16 cases, blue line). The outcomes for the 26 patients: Mean survival time: 33.6 months, 4-year Overall survival (OS): 37.0\%, 6-year OS: 31.7\%. Most of the 26 patients had either recurrent or far advanced cancers of the head and neck region and 15 (58\%) had regional lymph node metastases and 6 had developed distant metastases. Nineteen of the patients had squamous cell carcinomas, 4 salivary gland carcinomas and 3 had sarcomas. All but one had received standard therapy and developed recurrent tumors for which there were no other treatment options.

had surgery and conventionally fractionated photon irradiation with or without chemotherapy. Patients were evaluated prior to BNCT by means of ${ }^{18} \mathrm{PET}$ using ${ }^{18} \mathrm{~F}-\mathrm{BPA}$, whenever possible, and in order to be treated by BNCT the tumor to contralateral normal tissue ratio had to be at least 2.5:1. Patients who were treated with $\mathrm{BNCT}$ received two treatments at 3 to 5 week intervals. BPA-fructose
(400 mg/kg b.w.) was infused i.v. for $2 \mathrm{~h}$ prior to neutron irradiation, which was carried out at the Finnish BNCT facility in the outskirts of Helsinki. Neutron irradiation was performed via 2 ports; each with a median beam time of $18.6 \mathrm{~min}$. Cetirizine hydrochloride was administered orally prior to irradiation and dexamethasone (10-15 mg/d) afterwards, in order to alleviate radiation related edema.

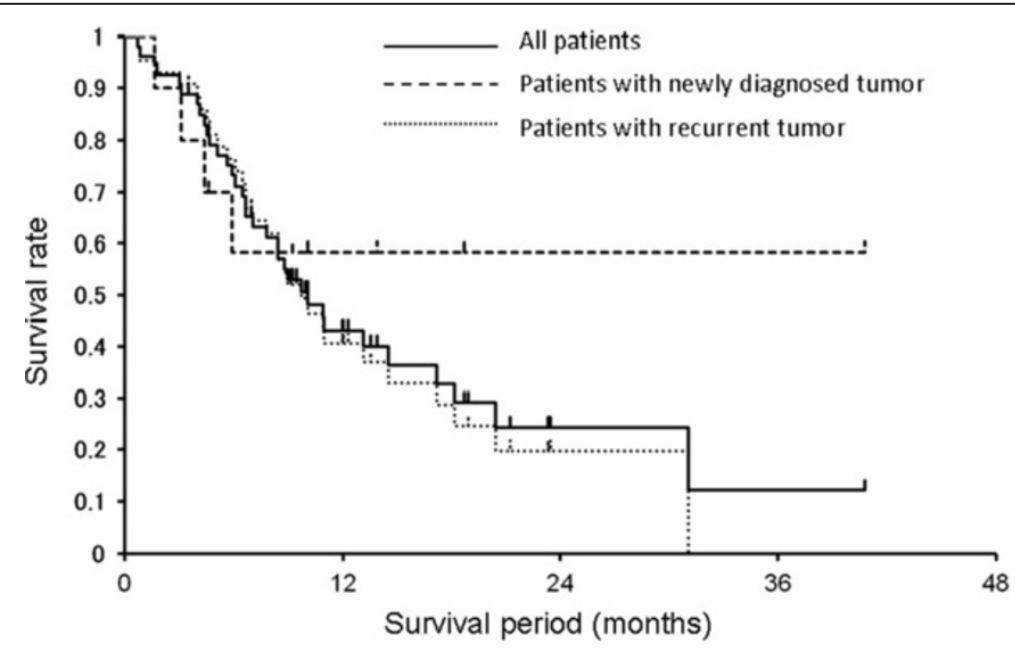

Figure 11 Kaplan-Meier survival plots of patients with either newly diagnosed or recurrent tumors of the head and neck region, treated by Suzuki et al. with BNCT. A total of 68 patients were treated. One and 2 year OS rates were $43.1 \%$ and $24.2 \%$ respectively. Thirty-three patients had squamous cell carcinomas (53\%), 20 had adenocarcinomas (32\%) and 11 (18\%) had malignant melanomas. 
Table 4 BNCT clinical trials using epithermal neutron beams for patients with recurrent or untreated unresectable head and neck cancer

\begin{tabular}{|c|c|c|c|c|c|c|}
\hline Medical institution & Neutron source & $\begin{array}{c}\text { Treatment } \\
\text { dates }\end{array}$ & $\begin{array}{l}\text { Tumor type \& } \\
\text { No. of patients }\end{array}$ & Boron compound $^{\mathrm{a}}$ & Clinical outcome & Ref. \\
\hline \multirow[t]{5}{*}{$\begin{array}{l}\text { Osaka University, Oral \& Maxillofacial } \\
\text { Surgery II, Osaka, Japan }\end{array}$} & \multirow{5}{*}{$\begin{array}{c}\text { KURR (Kyoto University Research Reactor, } \\
\text { Osaka, Japan) or JRR-4, Japan Atomic Energy } \\
\text { Agency, Tokai Research Establishment, } \\
\text { Ibaraki, Japan }\end{array}$} & \multirow[t]{5}{*}{$2001-2007$} & \multirow[t]{5}{*}{$26 \mathrm{rH} \& \mathrm{~N}$} & \multirow[t]{5}{*}{$\begin{array}{l}\text { BSH } 5 \mathrm{~g} \& \text { BPA } 250 \mathrm{mg} / \mathrm{kg} \text { in } 1 \mathrm{~h} \text { Or } \\
\text { BPA } 250-500 \mathrm{mg} / \mathrm{kg} \text { in } 1-2 \mathrm{~h}\end{array}$} & $\begin{array}{l}\text { MeST: } 7.9 \text { mos. } \\
\text { post BNCT }\end{array}$ & \multirow[t]{5}{*}[5,6]{, This Paper } \\
\hline & & & & & PR: $39 \%$ & \\
\hline & & & & & CR: $46 \%$ & \\
\hline & & & & & 2 \& 4 y OS: $37 \%$ & \\
\hline & & & & & 6 y OS: $32 \%$ & \\
\hline \multirow[t]{2}{*}{ Osaka Medical College, Osaka, Japan } & \multirow[t]{2}{*}{ KURR } & \multirow[t]{2}{*}{$2005-2008$} & \multirow[t]{2}{*}{$6 \mathrm{rOC}$} & \multirow{2}{*}{$\begin{array}{c}\text { BPA } 500 \mathrm{mg} / \mathrm{kg}(200 \mathrm{mg} / \mathrm{kg} \mathrm{h} \times 2 \mathrm{~h} ; \\
100 \mathrm{mg} / \mathrm{kg} \mathrm{h} \times \sim 1 \mathrm{~h} \text { during } \\
\text { irradiation })\end{array}$} & PR: $67 \%$ & \multirow[t]{2}{*}[113-115]{} \\
\hline & & & & & CR: $17 \%$ & \\
\hline \multirow{3}{*}{$\begin{array}{l}\text { Kyoto University Research Reactor } \\
\text { Institute (KURRI), Kyoto University, } \\
\text { Osaka, Japan }\end{array}$} & \multirow[t]{3}{*}{ KURR } & \multirow[t]{3}{*}{$2001-2007$} & $49 \mathrm{rH} \& \mathrm{~N}$ & \multirow[t]{3}{*}{ BSH \& BPA 250-500 mg/kg } & PR: 29\%, CR: $28 \%$ & \multirow{3}{*}{$\begin{array}{l}116,117] \\
\text { This paper }\end{array}$} \\
\hline & & & 13 urH\&N & & $\begin{array}{l}\text { MeST: } 10.1 \text { mos. } \\
\quad(n=53)\end{array}$ & \\
\hline & & & & & 2 y OS: $24 \%$ & \\
\hline \multirow{5}{*}{$\begin{array}{l}\text { Kawasaki Medical School, Kurashiki, } \\
\text { Japan }\end{array}$} & \multirow[t]{3}{*}{ KURR or JRR-4 } & \multirow[t]{3}{*}{$2003-2007$} & $10 \mathrm{rSqCC}$ & \multirow{3}{*}{$\begin{array}{c}\text { BPA } 500 \mathrm{mg} / \mathrm{kg}(200 \mathrm{mg} / \mathrm{kg} \mathrm{h} \times 2 \mathrm{~h} ; \\
100 \mathrm{mg} / \mathrm{kg} \mathrm{h} \times \sim 1 \mathrm{~h} \text { during } \\
\text { irradiation })\end{array}$} & PR: $35 \%$ & \multirow[t]{3}{*}[4,118,119]{} \\
\hline & & & $7 \mathrm{rnSqCC}$ & & $\begin{array}{l}\text { CR: } 55 \% \\
2 \text { y OS: } 32.3 \%\end{array}$ & \\
\hline & & & $3 \mathrm{nSqCC}$ & & & \\
\hline & \multirow[t]{2}{*}{ JRR-4 } & \multirow[t]{2}{*}{$2005-2008$} & \multirow[t]{2}{*}{$10 \mathrm{H} \& \mathrm{~N} M M$} & \multirow[t]{2}{*}{ BPA 500 mg/kg } & PR: $50 \%$ & \multirow[t]{2}{*}{ [120] } \\
\hline & & & & & CR: $40 \%$ & \\
\hline \multirow{6}{*}{$\begin{array}{l}\text { Helsinki University Central Hospital, } \\
\text { Helsinki, Finland }\end{array}$} & \multirow{6}{*}{$\begin{array}{l}\text { FiR-1, VTT Technical Research Centre, Espoo, } \\
\text { Finland }\end{array}$} & \multirow[t]{4}{*}{$2003-2008$} & $24 \mathrm{rSqCC}$ & \multirow[t]{4}{*}{ BPA $400 \mathrm{mg} / \mathrm{kg}$ in $2 \mathrm{~h}$} & PR: $31 \%$ & \multirow[t]{4}{*}{ [7] } \\
\hline & & & $6 \mathrm{rnSqCC}$ & & CR: $45 \%$ & \\
\hline & & & & & $\begin{array}{l}\text { MeST: } 13 \text { mos. } \\
\text { post BNCT }\end{array}$ & \\
\hline & & & & & 2 y OS: $30 \%$ & \\
\hline & & \multirow[t]{2}{*}{2010} & \multirow[t]{2}{*}{1 ur PDC } & BPA $400 \mathrm{mg} / \mathrm{kg}$ in $2 \mathrm{~h}$ & CR: $1 / 1$ & [121] \\
\hline & & & & $\begin{array}{l}\text { BNCT + Chemo-RT (IMRT + SRT) with } \\
\text { cetuximab and cisplatin }\end{array}$ & & \\
\hline Taipei Veterans General Hospital, & THOR, National Tsing Hua University, & $2010-2011$ & $10 \mathrm{rH} \& \mathrm{~N}$ & BPA 450 mg/kg (180 mg/kg h×2 h; & PR: $40 \%$ & {$[122,123]$} \\
\hline & & & & $\begin{array}{c}90 \text { mg/kg } \mathrm{h} \times \sim 1 \mathrm{~h} \text { during } \\
\text { irradiation) }\end{array}$ & CR: $30 \%$ & \\
\hline
\end{tabular}

\section{${ }^{a}$ This column also indicates treatment in cases of multi-modality treatment.}

Abbreviations: $r H \& N$ recurrent head and neck cancer, rOC recurrent oral cancer, ur unresectable, $r S q C C$ recurrent squamous cell carcinoma, rnSqCC recurrent non-squamous cell carcinoma, $n S C C$ non-squamous cell carcinoma (naïve), H\&N MM mucosal melanoma of the head and neck, PDC poorly differentiated carcinoma, XRT external beam radiation therapy (photons), IMRT intensity modulated radiation therapy, SRT stereotactic radiation therapy, $P R$ partial response, CR complete response, 2 y OS 2-year overall survival, MeST median survival time, given in months. 
More detailed information relating to other treatments that these patients received is provided in Kankaanranta et al.'s recent report [7]. Twenty-nine patients were evaluable with a median PFS of 7.5 months, of which 22 (76\%) responded, 6 (21\%) had stabilization of tumor growth for 5.1 and 20.3 months and 1 progressed. Two-year OS was $30 \%$ and PFS was $20 \%$ and $27 \%$ of the patients had no evidence of recurrent disease at 2 years. Mucositis and oral pain were the most common grade 3 adverse events, followed by fatigue, bone necrosis in 3 patients and soft tissue necrosis in one. Based on these results it was concluded that BNCT was effective for the treatment of inoperable locally recurrent, previously irradiated patients with head and neck cancer. Some responses were durable, but usually progression was common, most frequently at the site of the previously recurrent tumor.

\section{Study carried out in Taiwan}

Finally, ten patients with recurrent, late stage cancer of the head and neck region have been treated at the National Tsing Hua University THOR reactor in Taiwan using BPA as the boron delivery agent. At the time of this writing 3 of the 10 patients have had complete regressions at the site of treatment [122].

The clinical results described above clearly have demonstrated efficacy, something that has been less convincingly demonstrated in patients with high grade gliomas. This is hardly surprising since it took a large randomized EORTC trial $[124,125]$ with 590 glioma patients to convincingly demonstrate that the administration of temozolomide concomitantly with radiation therapy produced a significant increase in overall median survival compared to radiation therapy alone and this was only 2.5 months (14.6 versus 12.1 months)!

\section{Conclusions}

What then is the future of BNCT? It probably lies in filling a niche for those malignancies, whether primary or recurrent, for which there is no effective therapy. What are some of the advantages of BNCT? First, it has the ability to selectively deliver a high radiation dose to the tumor with a much lower dose to surrounding normal tissues. This is an important feature that makes BNCT particularly attractive for salvage therapy of patients who have been treated to tolerance with photon irradiation. Second, it has the potential to more effectively target multicentric deposits of tumor than is possible with stereotactic radiosurgery of primary and metastatic brain tumors. Third, although it may be only palliative, it can produce striking clinical responses, as evidenced by the experience of several groups treating patients with recurrent, therapeutically refractory head and neck cancer $[4-7,122]$. Furthermore, as is evident from data compiled in Table 2 summarizing the clinical results obtained in treating patients with either primary or recurrent high grade gliomas, there has been significant progress in improving the clinical results. Specifically, increasing the dose of BPA and administering it over a longer time period (92-95) or combining BNCT with a photon boost, as has been carried out in Japan (80), have resulted in the best survival data obtained to date using BNCT to treat patients with gliomas.

Critical issues that must be addressed include: 1 . Development of new low and high molecular weight boron agents and optimization of their delivery; 2. Obtaining approval for the clinical use of these new agents from regulatory agencies and carrying out biodistribution studies in patients prior to resection of their tumors; 3. Prioritizing collaborative efforts to compare and normalize dose prescriptions between centers, thus enabling studies on larger trial populations and perhaps facilitating multi-institutional or possibly randomized clinical trials; 4. Improvement of methods to determine the boron dose delivered to the residual tumor volume on both macroscopic and microscopic levels to enable more accurate tumor dose assessment. 5 . Be prepared to compete with or complement new therapeutic approaches. In this review we have summarized the current status of BNCT as a treatment for high grade gliomas and recurrent tumors of the head and neck region and outlined problems that we believe are important to solve in order to move forward with BNCT as a treatment modality. It is up to investigators, both in basic and clinical research, to come up with solutions to these problems.

\section{Abbreviations}

ABNS: Accelerator based neutron sources; ACNU: Aminochlorethyl nitrosourea; BMRR: Brookhaven Medical Research Reactor; BNCT: Boron neutron capture therapy; BNL: Brookhaven National Laboratory; BPA: Boronophenylalanine; BSH: Sodium borocaptate; CR: Complete response; CT: Computerized tomography; CTV: Clinical Target Volume; DVH: Dose volume histogram; EGFR: Epidermal growth factor receptor; EORTC: European Organization for Research and Treatment of Cancer;

FCB: Fission converter beam; FDG: Fluorodeoxyglucose; GBM: Glioblastoma multiforme; Gy: Weighted Gray; KURRl: Kyoto University Research Reactor Institute; L/N: Lesion to normal brain; MeST: Median survival time; MGH: Massachusetts General Hospital; MiMMC: Multi-Modal Monte Carlo; MIT: Massachusetts Institute of Technology; MITR: MIT Research Reactor; MoAb: Monoclonal antibody; MR: Magnetic resonance; MST: Mean survival time; MeST: Median survival time; MW: Megawatt; NCT: Neutron capture therapy; NV: Nanovehicle; OS: Overall survival; PDT: Photodynamic therapy; PET: Position emission tomography; PR: Partial response; TPS: Treatment planning system; VEGFR: Vascular endothelial growth factor receptor; WHO: World Health Organization.

\section{Competing interests}

The authors declare no competing interests.

\section{Authors' contributions}

RFB: Had overall responsibility for the preparation of this manuscript. Wrote the Abstract, Introduction and Conclusions. Contributed to the section on "Boron Delivery Agents." Contributed to the section on "Clinical studies of BNCT for brain tumors." Rewrote the section on "Clinical studies of BNCT for head and neck cancer." Compiled the references and integrated them into the text. MGHV: Wrote the section on "Boron delivery agents." OKH: Wrote the section on "Neutron sources for BNCT." WSK III: Wrote the section on "Clinical dosimetry and treatment planning" and contributed the related 
figures. Compiled the data and wrote the final versions of Tables 2, 3 and 4 KJR: Wrote the section on "Clinical dosimetry and treatment planning" and contributed the related figures. PJB: Wrote the section on "Clinical dosimetry and treatment planning" and contributed the related figures. FMW: Compiled the data and wrote the initial version of Tables 2 and 3. MS: Wrote the section "Clinical studies of BNCT for head and neck cancer" and contributed related figures. TA: Wrote the section "Clinical studies of BNCT for head and neck cancer" and contributed related figures. IK: Wrote the section "Clinical studies of BNCT for head and neck cancer" and contributed related figures. SK: Wrote the section on "Clinical studies of BNCT for brain tumors" and contributed related figures. All authors read and approved the final manuscript.

\section{Acknowledgements}

This paper is dedicated to Professor Emeritus Albert H. Soloway in celebration of his $87^{\text {th }}$ birthday. Dr. Barth thanks Mrs. Heidi Bosworth for expert secretarial assistance in the preparation of this manuscript. Research of Drs. Barth, Binns, Harling, Kiger, Riley and Vicente has been supported by numerous grants from the United States Department of Energy and the National Institutes of Health. Animal studies described in this review were carried out under protocols approved by the respective Institutional Animal Care and Use Committees and in accordance with the recommendations in the Guide for the Care and Use of Laboratory Animals of the National Institutes of Health. Dr. Kawabata's clinical studies have been supported by grants from the Ministry of Health, Labor and Welfare (MONBUSHO) from the government of Japan and were approved by the Ethical Committee of Osaka Medical College $($ No. 98, 218, 260) and by the BNCT Committee of Kyoto University Research Reactor Institute, Japan Atomic Energy Agency. Clinical studies that were carried out at Osaka University, Department of Oral and Maxillofacial Surgery II, were approved by the Ethics Committee of Osaka University Dental Hospital under approved Protocol H19-C1. Clinical studies carried out at Kawasaki Medical School, Okayama, Japan, were approved by the Institutional Ethical Committee.

\section{Author details}

'Department of Pathology, The Ohio State University, 165 Hamilton Hall, 1645 Neil Avenue, Columbus, OH 43210, USA. ${ }^{2}$ Department of Chemistry, Louisiana State University, Baton Rouge, LA 70803, USA. ${ }^{3}$ Department of Nuclear Science \& Engineering, Massachusetts Institute of Technology, Cambridge, MA 02139, USA. ${ }^{4}$ Department of Radiation Oncology, Beth Israel Deaconess Medical Center, Harvard Medical School, Boston, MA 02215, USA. ${ }^{5}$ Department of Radiation Oncology, Massachusetts General Hospital, Boston, MA 02114, USA. ${ }^{6}$ Department of Radiation Oncology, Mt. Auburn Hospital, Cambridge, MA 02138, USA. ${ }^{7}$ Forschungs-Neutronenquelle Heinz Maier-Leibnitz (FRM II), Technische Universität München, Garching, Germany. ${ }^{8}$ Particle Radiation Oncology Research Center, Kyoto University, Osaka, Japan. ${ }^{9}$ Department of Otolaryngology and Head and Neck Surgery, Kawasaki Medical School, Okayama, Japan. ${ }^{10}$ Department of Oral and Maxillofacial Surgery II, Graduate School of Dentistry, Osaka University, Osaka, Japan. ${ }^{11}$ Department of Neurosurgery, Osaka Medical College, Takatsuki City, Osaka, Japan.

Received: 14 June 2012 Accepted: 23 July 2012

Published: 29 August 2012

\section{References}

1. Barth RF, Coderre JA, Vicente MG, Blue TE: Boron neutron capture therapy of cancer: current status and future prospects. Clin Cancer Res 2005, 11:3987-4002.

2. Slatkin DN: A history of boron neutron capture therapy of brain tumours. Postulation of a brain radiation dose tolerance limit. Brain 1991, 114:1609-1629.

3. Barth RF: Boron neutron capture therapy: a critical assessment. J Neurooncol 2003, 62:1-210.

4. Aihara T, Hiratsuka J, Morita N, Uno M, Sakurai Y, Maruhashi A, Ono K, Harada T: First clinical case of boron neutron capture therapy for head and neck malignancies using 18 F-BPA PET. Head Neck 2006, 28:850-855.

5. Kato I, Ono K, Sakurai Y, Ohmae M, Maruhashi A, Imahori Y, Kirihata M, Nakazawa M, Yura Y: Effectiveness of BNCT for recurrent head and neck malignancies. Appl Radiat Isot 2004, 61:1069-1073.

6. Kato I, Fujita Y, Maruhashi A, Kumada H, Ohmae M, Kirihata M, Imahori Y, Suzuki M, Sakrai Y, Sumi T, et al: Effectiveness of boron neutron capture therapy for recurrent head and neck malignancies. Appl Radiat Isot 2009, 67:S37-S42.

7. Kankaanranta L, Seppälä T, Koivunoro H, Saarilahti K, Atula T, Collan J, Salli E, Kortesniemi M, Uusi-Simola J, Valimaki P, et al: Boron neutron capture therapy in the treatment of locally recurred head-and-neck cancer: final analysis of a phase I/II trial. Int J Radiat Oncol Biol Phys 2012, 82:e67-e75.

8. Altieri S, Barth RF, Bortolussi S, Roveda L, Zonta A: In 13th International Congress on Neutron Capture Therapy, A New Option Against Cancer. Appl Radiat Isot 2009, 67:S1-S379.

9. Kreiner A: 14th International Congress on Neutron Capture Therapy. Appl Radiat Isot 2011, 69:1631-1939.

10. Soloway AH, Tjarks W, Barnum BA, Rong FG, Barth RF, Codogni IM, Wilson JG: The chemistry of neutron capture therapy. Chem Rev 1998, 98:1515-1562.

11. Sibrian-Vazquez M, Vicente MGH: Boron tumor-delivery for BNCT: Recent developments and perspectives. In Boron Science: New Technologies \& Applications. Edited by Hosmane NS.: CRC Press; 2011:203-232.

12. Semioshkin A, Nizhnik E, Godovikov I, et al: Reactions of oxonium derivatives of $\left[\mathrm{B}^{12} \mathrm{H}^{12}\right]^{2-}$ with amines: Synthesis and structure of novel $B_{12}$-based ammonium salts and amino acids. V J Organomet Chem 2007, 692:4020-4028.

13. Kabalka GW, Wu Z, Yao M-L: Synthesis of a series of boronated unnatural cyclic amino acids as potential boron capture therapy agents. Appl Organomet Chem 2008, 22:516-522.

14. Kabalka GW, Yao ML, Marepally SR, Chandra S: Biological evaluation of boronated unnatural amino acids as new boron carriers. Appl Radiat Isot 2009, 67:S374-\$379.

15. Mier W, Gabel D, Haberkorn U: Conjugation of the closo-borane mereaptoundeca-hydrododecaborate $(\mathrm{BSH})$ to a tumor selective peptide. Anorg Allg Chem 2004, 630:1258-1262.

16. Al-Madhoun AS, Johnsamuel J, Barth RF, Tjarks W, Eriksson S: Evaluation of human thymidine kinase 1 substrates as new candidates for boron neutron capture therapy. Cancer Res 2004, 64:6280-6286.

17. Barth RF, Yang W, Wu G, Swindall M, Byun Y, Narayanasamy S, Tjarks W, Tordoff K, Moeschberger ML, Eriksson S, et al: Thymidine kinase 1 as a molecular target for boron neutron capture therapy of brain tumors. Proc Natl Acad Sci U S A 2008, 105:17493-17497.

18. Bregadze VI, Sivaev IB, Lobanova IA, Titeev RA, Brittal DI, Grin MA, Mironov AF: Conjugates of boron clusters with derivatives of natural chlorin and bacteriochlorin. Appl Radiat Isot 2009, 67:S101-S104.

19. Renner MW, Miura M, Easson MW, Vicente MG: Recent progress in the syntheses and biological evaluation of boronated porphyrins for boron neutron-capture therapy. Anticancer Agents Med Chem 2006, 6:145-157.

20. Ol'shevskaya V, Zaytsev A, Savchenko A, et al: Boronated porphyrins and chlorins as potential anticancer drugs. Bull Korean Chem Soc 2007, 28:1910-1916.

21. Kahl S, Koo M: Synthesis and properties of tebrakis-carborane-carboxylate esters of 2;4-bis (-dehydroryethyl) dereteroporphyrin IX. In Progress Neutron Capture Therapy. Edited by Allen B, Moore D, Harrington B. New York: Plenium Press; 1992:223-226.

22. Pan X, Wu G, Yang W, Barth RF, Tjarks W, Lee RJ: Synthesis of cetuximabimmunoliposomes via a cholesterol-based membrane anchor for targeting of EGFR. Bioconjug Chem 2007, 18:101-108.

23. Nakamura H: Liposomal boron delivery system for neutron capture therapy of cancer. In Boron Science: New Technologies and Applications. Edited by Hosmane N. CRC Press; 2012:165-179.

24. Altieri S, Balzi M, Bortolussi S, Bruschi P, Ciani L, Clerici AM, Faraoni P, Ferrari C, Gadan MA, Panza L, et al: Carborane derivatives loaded into liposomes as efficient delivery systems for boron neutron capture therapy. J Med Chem 2009, 52:7829-7835.

25. Feakes DA: Design and development of polyhedral borane anions for liposomal delivery. In Boron Science: New Technologies and Applications. Volume 12. Edited by Hosmane NS. CRC Press; 2011:277-292.

26. Li T, Hamdi J, Hawthorne MF: Unilamellar liposomes with enhanced boron content. Bioconjug Chem 2006, 17:15-20.

27. Capala J, Barth RF, Bendayan M, Lauzon M, Adams DM, Soloway AH, Fenstermaker RA, Carlsson J: Boronated epidermal growth factor as a potential targeting agent for boron neutron capture therapy of brain tumors. Bioconjug Chem 1996, 7:7-15.

28. Wu G, Yang W, Barth RF, Kawabata S, Swindall M, Bandyopadhyaya AK, Tjarks W, Khorsandi B, Blue TE, Ferketich AK, et al: Molecular targeting and treatment of an epidermal growth factor receptor positive glioma using boronated cetuximab. Clin Cancer Res 2007, 13:1260-1268. 
29. Yang W, Wu G, Barth RF, Swindall MR, Bandyopadhyaya AK, Tjarks W, Tordoff K, Moeschberger M, Sferra TJ, Binns PJ, et al: Molecular targeting and treatment of composite EGFR and EGFRvIll-positive gliomas using boronated monoclonal antibodies. Clin Cancer Res 2008, 14:883-891.

30. Backer MV, Gaynutdinov TI, Patel V, Bandyopadhyaya AK, Thirumamagal BT, Tjarks W, Barth RF, Claffey K, Backer JM: Vascular endothelial growth factor selectively targets boronated dendrimers to tumor vasculature. Mol Cancer Ther 2005, 4:1423-1429.

31. Yang W, Barth RF, Wu G, Kawabata S, Sferra TJ, Bandyopadhyaya AK, Tjarks W, Ferketich AK, Moeschberger ML, Binns PJ, et al: Molecular targeting and treatment of EGFRvIll-positive gliomas using boronated monoclonal antibody L8A4. Clin Cancer Res 2006, 12:3792-3802.

32. Yang W, Barth RF, Wu G, Huo T, Tjarks W, Ciesielski M, Fenstermaker RA, Ross BD, Wikstrand CJ, Riley KJ, Binns PJ: Convection enhanced delivery of boronated EGF as a molecular targeting agent for neutron capture therapy of brain tumors. J Neurooncol 2009, 95:355-365.

33. Yang W, Barth RF, Wu G, Tjarks W, Binns P, Riley K: Boron neutron capture therapy of EGFR or EGFRvIll positive gliomas using either boronated monoclonal antibodies or epidermal growth factor as molecular targeting agents. Appl Radiat Isot 2009, 67:\$328-\$331.

34. Crossley EL, Ziolkowski EJ, Coderre JA, Rendina LM: Boronated DNAbinding compounds as potential agents for boron neutron capture therapy. Mini Rev Med Chem 2007, 7:303-313.

35. Zhu $Y$, Yan $K$, Maguire J, et al: Recent developments in boron neutron capture therapy (BNCT) driven by nanotechnology. Curr Chem Biol 2007, 1:141-149.

36. Yinghuai Z, Cheng Yan K, Maguire JA: Recent developments in boron neutron capture therapy driven by nanotechnology. In Boron Science: New Technologies and Applications. Volume 1. Edited by Hosmane NS. CRC Press; 2007:147-163.

37. Doi A, Kawabata S, lida K, Yokoyama K, Kajimoto Y, Kuroiwa T, Shirakawa T, Kirihata M, Kasaoka S, Maruyama K, et al: Tumor-specific targeting of sodium borocaptate (BSH) to malignant glioma by transferrin-PEG liposomes: a modality for boron neutron capture therapy. J Neurooncol 2008, 87:287-294.

38. Ito Y, Kimura Y, Shimahara T, Ariyoshi Y, Shimahara M, Miyatake S, Kawabata S, Kasaoka S, Ono K: Disposition of TF-PEG-Liposome-BSH in tumorbearing mice. Appl Radiat Isot 2009, 67:S109-S110.

39. Pietrangeli D, Ricciardi G: Neutral and polyanionic carboranylporphyrazines: synthesis and physico-chemical properties. Appl Radiat Isot 2009, 67:S97-S100.

40. Menichetti L, De Marchi D, Calucci L, Ciofani G, Menciassi A, Forte C: Boron nitride nanotubes for boron neutron capture therapy as contrast agents in magnetic resonance imaging at 3 T. Appl Radiat Isot 2011 69:1725-1727

41. Bregadze VI, Sivaev IB: Polyhedral boron compounds for BNCT. In Boron Science: New Technologies and Applications. In. Edited by Hosmane N. CRC Press; 2012:181-208.

42. Orlova A, Kononov LO, Kimel BG, et al: Conjugates of polyhedral boron compounds with carbohydrates. 4 . Hydrolytic stability of carborane-lactose conjugates depends on the structure of a spacer between the carborane cage and sugar moiety. App/ Organometal Chem 2006, 20:416-420.

43. Moss RL, Aizawa O, Beynon D, Brugger R, Constantine G, Harling O, Liu HB, Watkins $P$ : The requirements and development of neutron beams for neutron capture therapy of brain cancer. J Neurooncol 1997, 33:27-40.

44. Harling OK: Fission reactor based epithermal neutron irradiation facilities for routine clinical application in BNCT-Hatanaka memorial lecture. Appl Radiat Isot 2009, 67:S7-S11

45. Harling OK, Riley KJ: Fission reactor neutron sources for neutron capture therapy - a critical review. J Neurooncol 2003, 62:7-17.

46. Zhou Y, Gao Z, Li Y, Guo C, Liu X: Design and construction of the inhospital neutron irradiator-1(HNI). In Proceed of 12th ICNCT - Advances in Neutron Capture Therapy 2006; October 9-13; Takamatsu, Japan. Edited by Nakagawa Y, Kobayashi T, Fukuda H: 2006:557-560.

47. Li Y, Xia P, Wang X, Kong F, Huang Q: Start-up of the first in-hospital Neutron Irradiator (IHNI1) \& presentation of the BNCT development status in China. In Proc 14th Int'l Cong on Neutron Capture Therapy, New Challenges in Neutron Capture Therapy 2010 Oct 25-29; Buenos Aires, Argentina. Edited by Liberman S, Kreiner AJ, Casal MR, Menendez P, Schwint A, Dragosa A, Cruz GS; 2010:371-374.
48. Harling OK, Riley KJ, Newton TH, et al: The fission converter based epithermal neutron ir-radiation facility at the Massachusetts Institute of Technology Reactor. Nucl Sci Eng 2002, 140:223-240.

49. Riley KJ, Binns PJ, Harling OK: Performance characteristics of the MIT fission converter based epithermal neutron beam. Phys Med Biol 2003, 48:943-958.

50. Blue TE, Yanch JC: Accelerator-based epithermal neutron sources for boron neutron capture therapy of brain tumors. J Neurooncol 2003, 62:19-31.

51. Nigg DW: Neutron sources and applications in radiotherapy- A brief history and current trends. In Advances in Neutron Capture Therapy 2006 Proc 12th Intl Cong Neutron Capture Therapy; Oct 9-13. Edited by Nakagawa Y, Kobayashi T, Fukuda H. Takamatsu, Japan; 2006.

52. Tanaka H, Sakurai $Y$, Suzuki M, Masunaga S, Mitsumoto T, Fujita K, Kashino G, Kinashi Y, Liu Y, Takada M, et al: Experimental verification of beam characteristics for cyclotron-based epithermal neutron source (C-BENS). Appl Radiat Isot 2011, 69:1642-1645

53. Coderre JA, Turcotte JC, Riley KJ, Binns PJ, Harling OK, Kiger WS III: Boron neutron capture therapy: cellular targeting of high linear energy transfer radiation. Technol Cancer Res Treat 2003, 2:355-375.

54. Rogus RD, Harling OK, Yanch JC: Mixed field dosimetry of epithermal neutron beams for boron neutron capture therapy at the MITR-II research reactor. Med Phys 1994, 21:1611-1625.

55. American Society for Testing and Materials: Standard test method for determining thermal neutron reaction and fluence rates by radioactivation techniques. West Conshohocken, PA; 1997.

56. Attix FH: Introduction to Radiological Physics and Radiation Dosimetry. New York: Wiley; 1986:475-501.

57. International Commission on Radiation Units and Measurements: Clinical Neutron Dosimetry, Part 1: Determination of Absorbed Dose in a Patient Treated by External Beams of Fast Neutrons. Bethesda, MD; 1989.

58. Zamenhof R, Redmond E, Solares G, Katz D, Riley K, Kiger S, Harling O: Monte Carlo-based treatment planning for boron neutron capture therapy using custom designed models automatically generated from $C T$ data. Int J Radiat Oncol Biol Phys 1996, 35:383-397.

59. Palmer MR, Goorley JT, Kiger WS III, Busse PM, Riley KJ, Harling OK, Zamenhof RG: Treatment planning and dosimetry for the Harvard-MIT Phase I clinical trial of cranial neutron capture therapy. Int J Radiat Oncol Biol Phys 2002, 53:1361-1379.

60. Nigg DW: Computational dosimetry and treatment planning considerations for neutron capture therapy. J Neurooncol 2003, 62:75-86.

61. Kiger WS III, Lu XQ, Harling OK, Riley KJ, Binns PJ, Kaplan J, Patel H, Zamenhof RG, Shibata Y, Kaplan ID, et al: Preliminary treatment planning and dosimetry for a clinical trial of neutron capture therapy using a fission converter epithermal neutron beam. Appl Radiat Isot 2004, 61:1075-1081.

62. Albritton JR: Computational aspects of treatment planning for neutron capture therapy. PhD thesis. Massachusetts Institute of Technology: Nuclear Science and Engineering; 2009.

63. Riley KJ, Binns PJ, Greenberg DD, Harling OK: A physical dosimetry intercomparison for BNCT. Med Phys 2002, 29:898-904.

64. Imahori $Y$, Ueda S, Ohmori Y, Kusuki T, Ono K, Fujii R, Ido T: Fluorine-18labeled fluoroboronophenylalanine PET in patients with glioma. J NuCl Med 1998, 39:325-333.

65. Miyashita M, Miyatake S, Imahori Y, Yokoyama K, Kawabata S, Kajimoto Y, Shibata MA, Otsuki Y, Kirihata M, Ono K, Kuroiwa T: Evaluation of fluoridelabeled boronophenylalanine-PET imaging for the study of radiation effects in patients with glioblastomas. J Neurooncol 2008, 89:239-246.

66. Binns PJ, Riley KJ, Harling OK, Auterinen I, Marek M, Kiger WS III: Progress with the NCT international dosimetry exchange. Appl Radiat Isot 2004, 61:865-868.

67. Binns PJ, Riley KJ, Harling OK, Kiger WS III, Munck af Rosenschold PM, Giusti V, Capala J, Skold K, Auterinen I, Seren T: An international dosimetry exchange for boron neutron capture therapy. Part I: Absorbed dose measurements. Med Phys 2005, 32:3729-3736.

68. Riley KJ, Binns PJ, Harling OK, Kiger WS III, Gonzalez SJ, Casal MR, Longhino J, Larrieu OA, Blaumann HR: Unifying dose specification between clinical BNCT centers in the Americas. Med Phys 2008, 35:1295-1298.

69. Riley KJ, Binns PJ, Harling OK, Albritton JR, Kiger WS III, Rezaei A, Skold K, Seppälä T, Savolainen S, Auterinen I, et al: An international dosimetry exchange for BNCT part II: Computational dosimetry normalizations. Med Phys 2008, 35:5419-5425.

70. Albritton JR, Kiger WS III: Neutron beam source definition techniques for NCT treatment planning. In Proceedings of the 13th International Congress 
on Neutron Capture Therapy: A New Option Against Cancer. Edited by Altieri S, Barth RF, Bortolussi S, Roveda L. Rome: ENEA; 2008:571-574.

71. Albritton JR, Kiger WS III: Development of reference problems for neutron capture therapy treatment planning systems. In Advances in Neutron Capture Therapy 2006. Edited by Nakagawa Y, Kobayashi T, Fukuda H. Takamatsu, Japan: International Society for Neutron Capture Therapy; 2006:496-499.

72. Locher GL: Biological effects and therapeutic possibilities of neutrons. Am J Roentgenol Radium Ther 1936, 36:1-13.

73. Sweet WH: Practical problems in the past in the use of boron-slow neutron capture therapy in the treatment of glioblastoma multiforme In Proceedings of the First International Symposium on Neutron Capture Therapy. 1983:376-378.

74. Farr LE, Sweet WH, Robertson JS, Foster CG, Locksley HB, Sutherland DL, Mendelsohn ML, Stickley EE: Neutron capture therapy with boron in the treatment of glioblastoma multiforme. Am J Roentgenol Radium Ther Nucl Med 1954, 71:279-293.

75. Asbury AK, Ojemann RG, Nielsen SL, Sweet WH: Neuropathologic study of fourteen cases of malignant brain tumor treated by boron-10 slow neutron capture radiation. J Neuropathol Exp Neurol 1972, 31:278-303.

76. Hatanaka H: Boron neutron capture therapy for brain tumors. In Glioma. Edited by Karim A, Laws E. Berlin: Springer-Verlag; 1991:233-249.

77. Nakagawa Y, Hatanaka H: Boron neutron capture therapy. Clinical brain tumor studies. J Neurooncol 1997, 33:105-115.

78. Soloway $A H$, Hatanaka H, Davis MA: Penetration of brain and brain tumor. VII. Tumor-binding sulfhydryl boron compounds. J Med Chem 1967, 10:714-717

79. Chanana AD, Capala J, Chadha M, Coderre JA, Diaz AZ, Elowitz EH, Iwai J, Joel DD, Liu HB, Ma R, et al: Boron neutron capture therapy for glioblastoma multiforme: interim results from the phase $1 /$ II doseescalation studies. Neurosurgery 1999, 44:1182-1192. discussion 1192-1183.

80. Diaz AZ: Assessment of the results from the phase $\mathrm{I} / \mathrm{Il}$ boron neutron capture therapy trials at the Brookhaven National Laboratory from a clinician's point of view. J Neurooncol 2003, 62:101-109.

81. Busse PM, Harling OK, Palmer MR, Kiger WS III, Kaplan J, Kaplan I, Chuang CF, Goorley JT, Riley KJ, Newton TH, et al: A critical examination of the results from the Harvard-MIT NCT program phase I clinical trial of neutron capture therapy for intracranial disease. J Neurooncol 2003, 62:111-121.

82. Chadha M, Capala J, Coderre JA, Elowitz EH, Iwai J, Joel DD, Liu HB, Wielopolski L, Chanana AD: Boron neutron-capture therapy (BNCT) for glioblastoma multiforme (GBM) using the epithermal neutron beam at the Brookhaven National Laboratory. Int J Radiat Oncol Biol Phys 1998, 40:829-834.

83. Wittig A, Hideghety K, Paquis P, Heimans J: Current Clinical Results of the EORTC-Study 11961. In Research and Development in Neutron Capture Therapy. Edited by Sauerwein W, Moss R, Wittig A. Bologna: Monduzzi Editore - International Proceedings Division; 2002:1117-1122.

84. Vos MJ, Turowski B, Zanella FE, Paquis P, Siefert A, Hideghety K, Haselsberger K, Grochulla F, Postma TJ, Wittig A, et al: Radiologic findings in patients treated with boron neutron capture therapy for glioblastoma multiforme within EORTC trial 11961. Int J Radiat Oncol Biol Phys 2005, 61:392-399.

85. Wittig A, Sauerwein W, Moss R, Stecher-Rasmussen F, Nivaart V, Grabbe S, Heimans J, Collette L, Loenen A, Buehrmann S, et al: Early phase II study on BNCT in metastatic malignant melanoma using the boron carrier BPA (EORTC protocol 11011). In Advances in Neutron Capture Therapy 2006. Edited by Nakagawa Y, Kobayashi T, Fukuda H. Takamatsu, Japan: International Society for Neutron Capture Therapy; 2006:284-287.

86. Joensuu H, Kankaanranta L, Seppala T, Auterinen I, Kallio M, Kulvik M, Laakso J, Vahatalo J, Kortesniemi M, Kotiluoto P, et al: Boron neutron capture therapy of brain tumors: clinical trials at the finnish facility using boronophenylalanine. J Neurooncol 2003, 62:123-134.

87. Kankaanranta L, Koivunoro H, Kortesniemi M, Välimäki $P$, Seppälä T, Kotiluoto P, Auterinen I, Kouri M, Savolainen S, Joensuu H: BPA-Based BNCT in the treatment of glioblastoma multiforme: A dose escalation study. In 13th International Congress on Neutron Capture Therapy, A New Option Against Cancer; November 2-7; Florence, Italy. Edited by Zonta A, Altieri S, Roveda L, Barth RF. 2008:30.

88. Kankaanranta L, Seppälä T, Koivunoro H, Valimaki P, Beule A, Collan J, Kortesniemi M, Uusi-Simola J, Kotiluoto P, Auterinen I, et al: L- boronophenylalanine-mediated boron neutron capture therapy for malignant glioma progressing after external beam radiation therapy: a Phase I study. Int J Radiat Oncol Biol Phys 2011, 80:369-376.

89. Burian J, Marek M, Rataj J, Flibor S, Rejchrt J, Viererbl L, Sus F: Report on the first patient group of the phase I BNCT trial at the LVR-15 reactor. Int Congress Series 2004, 1259:27-32.

90. Capala J, Stenstam BH, Sköld K, Munck af Rosenschold P, Giusti V, Persson C, Brun A, Franzen L, Carlsson J, et al: Boron neutron capture therapy for glioblastoma multiforme: clinical studies in Sweden. J Neurooncol 2003, 62:135-144.

91. Henriksson R, Capala J, Michanek A, LindahI SA, Salford LG, Franzen L, Blomquist E, Westlin JE, Bergenheim AT: Boron neutron capture therapy (BNCT) for glioblastoma multiforme: a phase II study evaluating a prolonged high-dose of boronophenylalanine (BPA). Radiother Oncol 2008, 88:183-191.

92. Sköld K, Stenstam BH, Diaz AZ, Giusti V, Pellettieri L, Hopewell JW: Boron neutron capture therapy for glioblastoma multiforme: advantage of prolonged infusion of BPA-f. Acta Neurol Scand 2010, 122:58-62.

93. Sköld K, Gorlia T, Pellettieri L, Giusti V, HS B, Hopewell JW: Boron neutron capture therapy for newly diagnosed glioblastoma multiforme: an assessment of clinical potential. Br J Radio/ 2010, 83:596-603.

94. Stenstam BH, Pellettieri L, Sorteberg W, Rezaei A, Skold K: BNCT for recurrent intracranial meningeal tumours - case reports. Acta Neurol Scand 2007, 115:243-247.

95. Pellettieri L, HS B, Rezaei A, Giusti V, Skold K: An investigation of boron neutron capture therapy for recurrent glioblastoma multiforme. Acta Neurol Scand 2008, 117:191-197.

96. Yamamoto T, Matsumura A, Nakai K, Shibata Y, Endo K, Sakurai F, Kishi T, Kumada H, Yamamoto K, Torii Y: Current clinical results of the Tsukuba BNCT trial. Appl Radiat Isot 2004, 61:1089-1093.

97. Yamamoto T, Nakai K, Kageji T, Kumada H, Endo K, Matsuda M, Shibata Y, Matsumura A: Boron neutron capture therapy for newly diagnosed glioblastoma. Radiother Oncol 2009, 91:80-84.

98. Kageji T, Nagahiro S, Matsuzaki K, Mizobuchi Y, Toi H, Nakagawa Y, Kumada $\mathrm{H}$ : Boron neutron capture therapy using mixed epithermal and thermal neutron beams in patients with malignant glioma-correlation between radiation dose and radiation injury and clinical outcome. Int J Radiat Oncol Biol Phys 2006, 65:1446-1455.

99. Kageji T, Mizobuchi Y, Nagahiro S, Nakagawa $Y$, Kumada $\mathrm{H}$ : Clinical results of boron neutron capture therapy (BNCT) for glioblastoma. Appl Radiat Isot 2011, 69:1823-1825.

100. Kageji T, Mizobuchi Y, Nagahiro S, Nakagawa Y, Kumada H: Long-survivors of glioblatoma treated with boron neutron capture therapy (BNCT). Appl Radiat Isot 2011, 69:1800-1802.

101. Miyatake S, Kawabata S, Kajimoto Y, Aoki A, Yokoyama K, Yamada M, Kuroiwa T, Tsuji M, Imahori Y, Kirihata M, et al: Modified boron neutron capture therapy for malignant gliomas performed using epithermal neutron and two boron compounds with different accumulation mechanisms: an efficacy study based on findings on neuroimages. J Neurosurg 2005, 103:1000-1009.

102. Kawabata S, Miyatake S, Kuroiwa T, Yokoyama K, Doi A, lida K, Miyata S, Nonoguchi N, Michiue H, Takahashi M, et al: Boron neutron capture therapy for newly diagnosed glioblastoma. J Radiat Res (Tokyo) 2009, 50:51-60.

103. Miyatake S, Kawabata S, Yokoyama K, Kuroiwa T, Michiue H, Sakurai Y, Kumada H, Suzuki M, Maruhashi A, Kirihata M, Ono K: Survival benefit of boron neutron capture therapy for recurrent malignant gliomas. J Neurooncol 2009, 91:199-206.

104. Miyatake S, Tamura Y, Kawabata S, lida K, Kuroiwa T, Ono K: Boron neutron capture therapy for malignant tumors related to meningiomas. Neurosurgery 2007, 61:82-90. discussion 90-81.

105. Tamura Y, Miyatake S, Nonoguchi N, Miyata S, Yokoyama K, Doi A, Kuroiwa T, Asada M, Tanabe H, Ono K: Boron neutron capture therapy for recurrent malignant meningioma. Case report. J Neurosurg 2006, 105:898-903.

106. Kawabata S, Miyatake S, Hiramatsu R, Hirota Y, Miyata S, Takekita Y, Kuroiwa T, Kirihata M, Sakurai Y, Maruhashi A, Ono K: Phase II clinical study of boron neutron capture therapy combined with X-ray radiotherapy/temozolomide in patients with newly diagnosed glioblastoma multiforme-study design and current status report. App/ Radiat Isot 2011, 69:1796-1799.

107. Barth RF, Grecula JC, Yang W, Rotaru JH, Nawrocky M, Gupta N, Albertson BJ, Ferketich AK, Moeschberger ML, Coderre JA, Rofstad EK: Combination of boron neutron capture therapy and external beam radiotherapy for brain tumors. Int J Radiat Oncol Biol Phys 2004, 58:267-277. 
108. Yamamoto T, Nakai K, Nariai T, Kumada H, Okumura T, Mizumoto M, Tsubo K, Zaboronok A, Ishikawa E, Aiyama H, et al: The status of Tsukuba BNCT trial: BPA-based boron neutron capture therapy combined with X-ray irradiation. App/ Radiat Isot 2011, 69:1817-1818.

109. Aiyama H, Nakai K, Yamamoto T, Nariai T, Kumada H, Ishikawa E, Isobe T, Endo K, Takada T, Yoshida F, et al: A clinical trial protocol for second line treatment of malignant brain tumors with BNCT at University of Tsukuba. Appl Radiat Isot 2011, 69:1819-1822.

110. Nakai K, Yamamoto T, Aiyama H, Takada T, Yoshida F, Kageji T, Kumada H, Isobe T, Endo K, Matsuda M, et al: Boron neutron capture therapy combined with fractionated photon irradiation for glioblastoma: a recursive partitioning analysis of BNCT patients. App/ Radiat Isot 2011, 69:1790-1792.

111. Smith DR, Chandra S, Barth RF, Yang W, Joel DD, Coderre JA: Quantitative imaging and microlocalizaton of boron-10 in brain tumors and infiltrating tumor cells by SIMS ion microscopy: Relevance to neutron capture therapy. Cancer Res 2001, 61:8179-8187.

112. Hopewell JW, Gorlia T, Pellettieri L, Giusti V, Stenstam BH, Skold K: Boron neutron capture therapy for newly diagnosed glioblastoma multiforme: an assessment of clinical potential. Appl Radiat Isot 2011, 69:1737-1740.

113. Ariyoshi Y, Miyatake S, Kimura Y, Shimahara T, Kawabata S, Nagata K, Suzuki M, Maruhashi A, Ono K, Shimahara M: Boron neuron capture therapy using epithermal neutrons for recurrent cancer in the oral cavity and cervical lymph node metastasis. Oncol Rep 2007, 18:861-866.

114. Kimura Y, Ariyoshi Y, Miyatake S, Shimahara M, Kawabata S, Ono K: Boron neutron capture therapy for papillary cystadenocarcinoma in the upper lip: a case report. Int J Oral Maxillofac Surg 2009, 38:293-295.

115. Kimura Y, Ariyoshi Y, Shimahara M, Miyatake S, Kawabata S, Ono K, Suzuki M, Maruhashi A: Boron neutron capture therapy for recurrent oral cancer and metastasis of cervical lymph node. Appl Radiat Isot 2009, 67:S47-S49.

116. Suzuki M, Sakurai Y, Nagata K, Kinashi Y, Masunaga S, Ono K, Maruhashi A, Kato I, Fuwa N, Hiratsuka J, Imahori Y: Impact of intra-arterial administration of boron compounds on dose-volume histograms in boron neutron capture therapy for recurrent head-and-neck tumors. Int J Radiat Oncol Biol Phys 2006, 66:1523-1527.

117. Fuwa N, Suzuki M, Sakurai Y, Nagata K, Kinashi Y, Masunaga S, Maruhashi A, Imahori $Y$, Kodaira T, Tachibana H, et al: Treatment results of boron neutron capture therapy using intra-arterial administration of boron compounds for recurrent head and neck cancer. Br J Radio/ 2008, 81:749-752.

118. Aihara T, Hiratsuka J, Nishhiike S, Morita N, Uno M, Maruhashi A, Kumada H, Ono K, Harada T: Boron neutron capture therapy for head and neck epithelial carcinomas other than SCC. In 13th International Congress on Neutron Capture Therapy, A New Option Against Cancer; November 2-7; Florence, Italy. Edited by Zonta A, Altieri S, Roveda L, Barth RF; 2008:31-33.

119. Aihara T, Morita N, Hiratsuka J, Ono K, Harada T, et al: BNCT for advanced or recurrent head and neck cancer. In Special Issue: $14^{\text {th }}$ International Congress on Neutron Capture Therapy. Edited by Kreiner AJ, Appl Radiat I. 2011:25-28.

120. Fukutsuji K, Aihara T, Hiratsuka J, Kumada H, Ono K, Sakurai Y, Fukuda H, Morita N, Imajo Y: Boron neutron capture therapy for patients with melanomas of head-and-neck. In 13th International Congress on Neutron Capture Therapy, A New Option Against Cancer; November 2-7; Florence, Italy. Edited by Zonta A, Altieri S, Roveda L, Barth RF; 2008:83-85.

121. Kankaanranta L, Saarilahti K, Makitie A, Valimaki $P$, Tenhunen M, Joensuu H: Boron neutron capture therapy (BNCT) followed by intensity modulated chemoradiotherapy as primary treatment of large head and neck cancer with intracranial involvement. Radiother Oncol 2011, 99:98-99.

122. Wang LW, Wang SJ, Chu PY, Ho CY, Jiang SH, Liu YW, Liu YH, Liu HM, Peir JJ, Chou Fl, et al: BNCT for locally recurrent head and neck cancer: preliminary clinical experience from a phase $\mathrm{I} / \mathrm{II}$ trial at Tsing Hua open-pool reactor. Appl Radiat Isot 2011, 69:1803-1806.

123. Wang LW, Wang SJ, Chu PY, Ho CY, Jiang SH, Chou Fl, Liu YWH, Liu YH, Liu $\mathrm{HM}$, Peir JJ, et al: Preliminary clinical experience of boron neutron capture therapy for locally recurrent head and neck cancer at Tsing Hua Open Pool Reactor. In The Front Edge of BNCT Development: Proceedings of the 6th Young Researchers Boron Neutron Capture Therapy Meeting; Dec. 4-8, 2011; Hsinchu, Taiwan. Edited by Jiang SH, Liu Y-H; 2011:257.

124. Stupp R, Mason WP, van den Bent MJ, Weller M, Fisher B, Taphoorn MJ, Belanger K, Brandes AA, Marosi C, Bogdahn U, et al: Radiotherapy plus concomitant and adjuvant temozolomide for glioblastoma. N Engl J Med 2005, 352:987-996.
125. Stupp R, Hegi ME, Mason WP, van den Bent MJ, Taphoorn MJ, Janzer RC, Ludwin SK, Allgeier A, Fisher B, Belanger K, et al: Effects of radiotherapy with concomitant and adjuvant temozolomide versus radiotherapy alone on survival in glioblastoma in a randomised phase III study: 5-year analysis of the EORTC-NCIC trial. Lancet Oncol 2009, 10:459-466.

doi:10.1186/1748-717X-7-146

Cite this article as: Barth et al:: Current status of boron neutron capture therapy of high grade gliomas and recurrent head and neck cancer. Radiation Oncology 2012 7:146.

\section{Submit your next manuscript to BioMed Central and take full advantage of:}

- Convenient online submission

- Thorough peer review

- No space constraints or color figure charges

- Immediate publication on acceptance

- Inclusion in PubMed, CAS, Scopus and Google Scholar

- Research which is freely available for redistribution

Submit your manuscript at www.biomedcentral.com/submit
C Biomed Central 